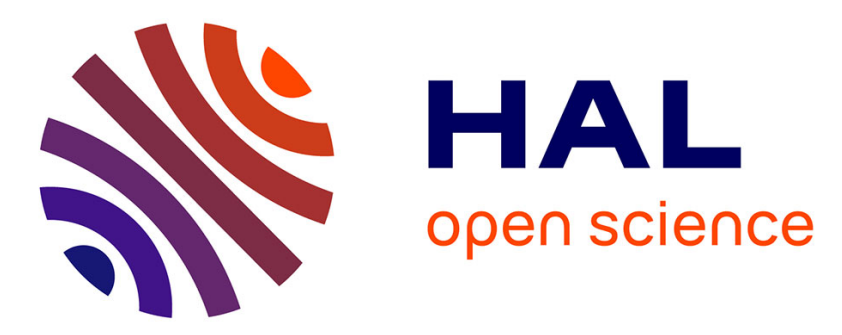

\title{
Structural analysis of sputtered amorphous silica thin films: A Raman spectroscopy investigation
}

S Ben Khemis, E. Burov, H. Montigaud, D. Skrelic, E. Gouillart, L. Cormier

\section{To cite this version:}

S Ben Khemis, E. Burov, H. Montigaud, D. Skrelic, E. Gouillart, et al.. Structural analysis of sputtered amorphous silica thin films: A Raman spectroscopy investigation. Thin Solid Films, 2021, 733, pp.138811. 10.1016/j.tsf.2021.138811 . hal-03290541

\section{HAL Id: hal-03290541 \\ https://hal.science/hal-03290541}

Submitted on 19 Jul 2021

HAL is a multi-disciplinary open access archive for the deposit and dissemination of scientific research documents, whether they are published or not. The documents may come from teaching and research institutions in France or abroad, or from public or private research centers.
L'archive ouverte pluridisciplinaire HAL, est destinée au dépôt et à la diffusion de documents scientifiques de niveau recherche, publiés ou non, émanant des établissements d'enseignement et de recherche français ou étrangers, des laboratoires publics ou privés. 


\title{
Structural analysis of sputtered amorphous silica thin films: a Raman spectroscopy investigation
}

\author{
S. Ben Khemis ${ }^{a}$,, E. Burov ${ }^{a}$, H. Montigaud ${ }^{a}$, D. Skrelic ${ }^{a}$, E.Gouillarta ${ }^{a}$ L. Cormier ${ }^{b}$
}

a Surface du Verre et Interfaces (UMR 125), CNRS/Saint-Gobain Research Paris, 39 quai Lucien Lefranc, 93300 Aubervilliers, France

${ }^{b}$ Sorbonne Université, CNRS UMR7590, MNHN, IRD, Institut de minéralogie, de physique des matériaux et de cosmochimie (IMPMC), 4 place Jussieu, F-75005 Paris, France

\begin{abstract}
:
In this work, a structural characterization of sputtered silica films was carried out using Raman spectroscopy. Due to the low cross-section and the thinness of the silica layer, its Raman signature is dwarfed by that of the glass substrate and is therefore difficult to extract. Overcoming these limitations represents an experimental challenge and requires the development of specific analysis strategies. For this purpose, an integrated approach for extracting and interpreting the Raman signature of amorphous silica films deposited on a soda-lime glass substrate was developed, based on three distinct methods: delamination of the sputtered silica film, creating a reflective mask substrate by depositing a metallic silver coating on the glass substrate and applying a numerical signal analysis (Non-negative matrix factorization) to the multidimensional dataset acquired through depth profile acquisitions on silica films directly deposited on a glass substrate. The reliability of each proposed method is demonstrated for the extraction of the silica thin film Raman spectra. These various methods can be easily extended to other materials, either crystalline or amorphous. Furthermore, we discuss the advantages and the limits of each approach.
\end{abstract}

Applying this methodology allowed us to highlight the structural differences between sputtered silica thin film and bulk vitreous silica glass (v-SiO2). Magnetron sputtering film deposition is shown to form dense silica glass layers, with an estimated densification ratio, 
measured by $x$-ray reflectivity, equal to $7 \%$. At the medium distance range, the network connectivity change in $\mathrm{v}-\mathrm{SiO}_{2}$ is expressed by an unusually high population of three-membered rings leading to a more compact structure. The short-range order transformation was also studied by deriving the intertetrahedral angle decrease. The present results could be a step towards advanced investigation to gain insights into the structure of films at the atomic level.

Keywords: Magnetron sputtering; Thin films; Silicon oxide; Densification; Raman spectroscopy; Deconvolution 


\section{Introduction}

Owing to their optical and chemical properties, silicon dioxide-based thin films are widely used materials for many applications in optics [1]-[2], micro-electromechanical systems [3][4], microelectronics as gate insulators [5]-[6], photovoltaics as a passivating layers [7]-[8] and as a chemical diffusion barrier for functionalization of float glasses [9]-[10]. Silica films can be grown by several deposition processes, including sol-gel method [11], ion-assisted deposition (IAD) [12], thermal oxidation [13], physical vapor deposition (PVD) [10] and chemical vapor deposition (CVD) [14]. Depending on the deposition method, the resulting films exhibit quite different macroscopic properties due to the number of interrelated process parameters and due to the increased surface to volume ratio with decreasing film thickness, from a few microns (e.g. sol-gel technique) to a fraction of a nanometer (e.g. PVD).

The elaboration of $\mathrm{SiO}_{2}$ films results usually in an amorphous material [15], a-SiO 2 , with subtle structural differences linked to the fabrication methods and the applied growth conditions. The change of the microscopic structure may lead to different dielectric [16], optical [17] and mass-density [18] properties of the films. Conventionally, vitreous bulk silica glass $\left(\mathrm{v}-\mathrm{SiO}_{2}\right)$ structure is as a corner-sharing $\mathrm{SiO}_{4}$ tetrahedral network arranged in non-planar rings ( $\mathrm{Si}-\mathrm{O}-$ $\mathrm{Si})_{n}$ of various shapes and sizes [19], with $n$ the number of $\mathrm{SiO}_{4}$ tetrahedra involved within a ring. The $n$ distribution, characterizing the medium-range order of vitreous silica $\left(v-\mathrm{SiO}_{2}\right)$, varies from 3 to 10 -fold rings with the most probable ring being six-membered [20]. This relatively open structure leads to a free volume fraction greater in silica than in other network glasses, such as $\mathrm{GeO}_{2}$ [21]. This allows a high densification, up to $\sim 20 \%$, under certain conditions (pressure, temperature, irradiation). In response to these external stresses, the fraction of small 3 and 4 fold rings [22] greatly varies with compression [23]-[24]-[25], thermal quenching rate [26] and neutron/electron irradiation [26]-[27]. There are much technological and fundamental interest in gaining a deep understanding of the structural features of silica thin films. Unlike bulk glass, for which many techniques are widely used to determine the structure [28]-[29]-[30]-[31], the structural analysis of amorphous thin films is challenging due to the weak signal of disordered materials and due to the small film thickness, resulting in possible overlap of signals from the thin film and the substrate. For instance, the structure of a-SiO ${ }_{2}$ thin films has been investigated using Grazing-Incidence Wide-Angle X-ray Scattering and Small-Angle X-ray Scattering measurements revealing that the fabrication process (specifically the oxidation conditions) affects the short range order [32]. From a fundamental 
point of view, a recent study by direct imaging of monolayer $\mathrm{SiO}_{2}$ films has confirmed the Zachariasen's model of a continuous random network that has been used for 80 years to describe the glass structure of $\mathrm{SiO}_{2}$ and other oxide glasses [33]. Among the available techniques, Raman scattering spectroscopy is an appropriate tool to gain insights into the structure at the atomic level of materials, including glasses [31]-[34]-[35].

For film structure investigation, thick films up to the micrometer scale allowing depth profile with confocal Raman microscopy [36]-[37] or materials with a high Raman cross-section are mostly investigated to get an exploitable Raman signal [38]-[39]-[40]. For instance, this technique is frequently used to investigate amorphous thin films with high-intensity Raman answer, in particular silicon, carbon [40]-[41]-[42]-[43] and chalcogenides [44]-[45]. For thin films $(<1 \mu \mathrm{m})$, specific substrates (fluorides) with a low Raman background signal can be used [46]-[47] and, in some specific cases, surface-enhanced Raman scattering has a beneficial influence on the thin film signal intensity [48]-[49]. However, some practical applications require to deposit an amorphous silica thin film onto a silicate glass substrate. In this case, it is highly challenging to obtain an accurate Raman spectra of the layer due to the similarity between the two Raman signals. This makes the subtraction of the substrate background difficult and leads to inconsistent or inaccurate results [50]. In consequence, the number of Raman structural investigations on amorphous silica thin film $(<1 \mu \mathrm{m})$, that has additionally a low Raman cross-section [51], is very limited [52]. To overcome these problems, a particularly attractive solution is the use of statistical methods that were developed as an alternative approach to classical analysis of Raman spectra relying on the spectral decomposition by a sum of Gaussian or pseudo-Voigt functions. Recently, the non-negative Matrix Factorization (NMF) technique [53]-[54]-[55] has gained huge attention in many applications. It was used as a powerful tool for deconvolution of Raman spectra of bulk glasses. Indeed, coupled with chemical composition analysis, NMF has been applied to isolate the specific signatures of different components in binary [56] and ternary [57] glasses. The extraction of the polymerization degree from the Raman spectra deconvolution has offered insightful information on the connectivity of the silicate network along compositional profiles [57].

In the present work, we tackle the problem of Raman structural characterization of silica thin films having a low Raman signal. We present three approaches to obtain the Raman spectrum of thin silica film $(<1 \mu \mathrm{m})$. The first two methods aim to eliminate the glass substrate signal and to record exclusively the characteristic Raman spectra of the silica film. The first 
developed technique is based on a specific sample preparation that consists in separating the silica layer from the substrate, using a recovering process without altering the film structure. The second approach consists in the preparation of a specific substrate, a reflective mask substrate, by depositing a silver coating between the glass substrate and the silica film. Finally, the last approach is based on the application of the NMF technique. This multivariate data analysis, without any sample preparation, is applied on the Raman depth acquisitions of silica film directly deposited on a glass substrate. The comparison of these three methods to each other allows us to confirm their feasibility as similar thin film Raman spectra are obtained. This structural characterization reveals considerable differences between $\mathrm{v}^{-\mathrm{SiO}_{2}}$ glass and sputtered silica film.

\section{Sample preparation}

As illustrated in Table 1, to investigate the silica film structure, three different systems were prepared in the present work. They are described in section 2.1 and 2.2. The substrate used for all coating depositions is a commercial soda-lime silicate glass (Planiclear ${ }^{\circledR}$ ).

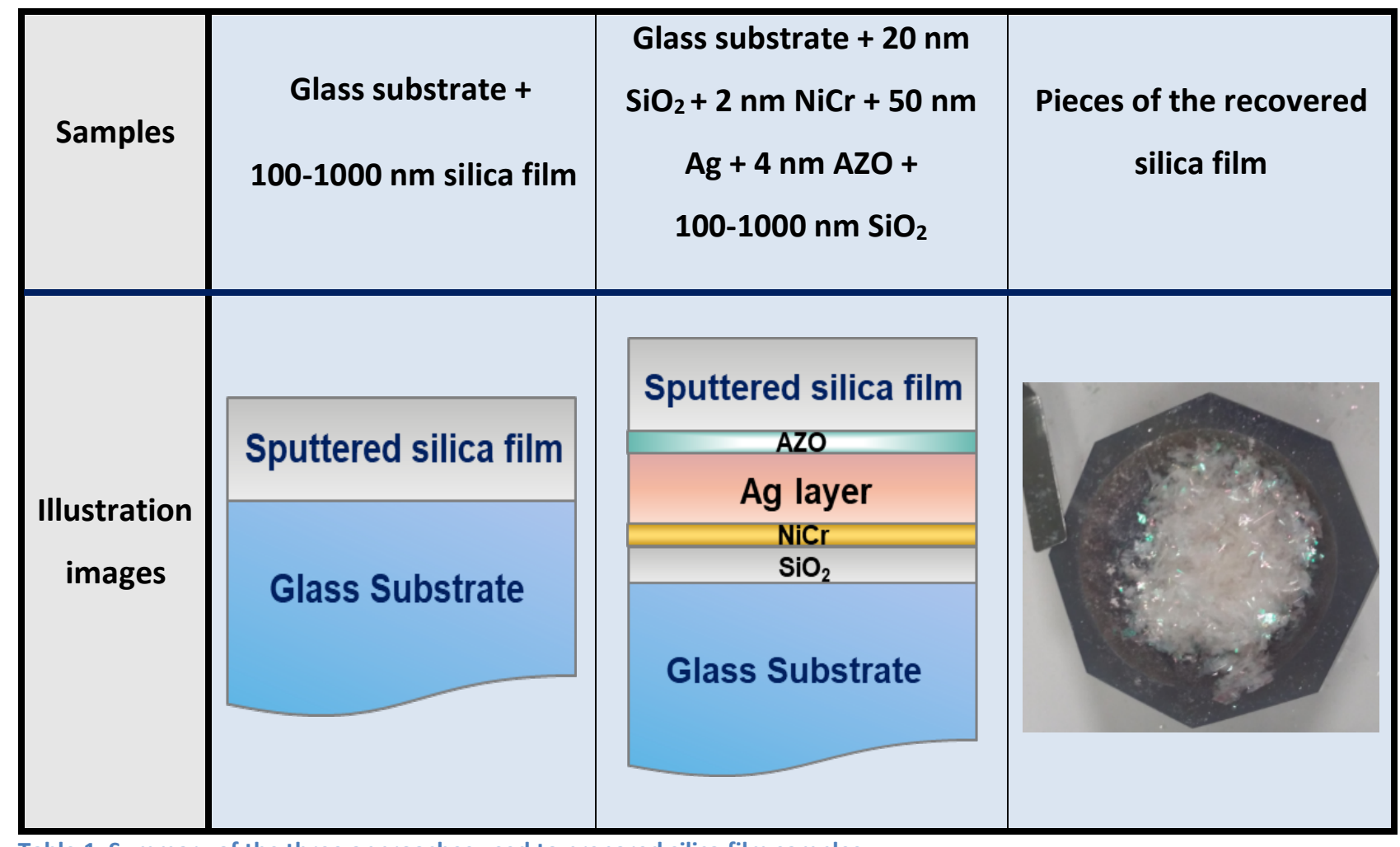

Table 1: Summary of the three approaches used to prepared silica film samples. 


\subsection{Silica film deposition}

Silica glass films with thicknesses ranging from $100 \mathrm{~nm}$ to $1000 \mathrm{~nm}$ were deposited by cathodic magnetron-sputtering, a Physical Vapor Deposition (PVD) process, at room temperature and under reactive atmosphere at $0.2 \mathrm{~Pa}$ in $\left(\mathrm{Ar}: 20 \mathrm{sccm} / \mathrm{O}_{2}: 24 \mathrm{sccm}\right)$ plasma. To determine the required $\mathrm{O}_{2}$ flow rate, the hysteresis curve for the system was obtained before deposition. The gas flow rates were monitored using mass flow controllers. A planar metallic target of silicon (Si), containing some Al contaminations, was operated in direct current (DC) at a frequency of $100 \mathrm{kHz}$ and $4.0 \mu \mathrm{sec}$ off time, for silica films deposition. Glass substrates were scrolled under the Si target with a deposition rate of $0.045 \mathrm{~m} \cdot \mathrm{min}^{-1}$ at a power of $3000 \mathrm{~W}$. The residual pressure was $10^{-7}$ mbar. Before deposition, the silicon target was pre-sputtered for $15 \mathrm{~min}$ to remove surface contamination. As seen in Table 1, silica layers were deposited both on a commercial Saint-Gobain Planiclear ${ }^{\circledR}$ flat glass substrate with a thickness of $2 \mathrm{~mm}$ and on a glass substrate pre-coated with a silver layer of $50 \mathrm{~nm}$ thickness deposited on a $\mathrm{SiO}_{2}(20 \mathrm{~nm})$ / $\mathrm{NiCr}(2 \mathrm{~nm})$ stack as a seed layer to enhance silver adhesion. Table 2 presents the experimental parameters used for the deposition of the different films. Furthermore, the $\mathrm{Ag}$ layer was capped with a thin Al-doped zinc oxide (AZO) layer $(4 \mathrm{~nm})$ to prevent silver oxidation during the silica deposition and to maintain its performance in reflection, which is directly related to its conductivity. This substrate will be called "a reflective mask substrate". The Ag layer is used as a reflecting coating that masks the Raman signal of the glass substrate to obtain only that of the sputtered silica film. Before deposition, the glass surfaces were cleaned with RBS $^{\mathrm{TM}} 50$ solution, a special liquid alkaline detergent for glass, rinsed with deionized water and dried using $\mathrm{N}_{2}$ flux.

\begin{tabular}{|l|c|c|c|c|}
\hline Target & Si & Ag & NiCr & AZO \\
\hline Power (W) & 3000 & 500 & 500 & 1300 \\
\hline Pressure (Pa) & 0.2 & 0.8 & 0.2 & 0.2 \\
\hline Ar flow (sccm) & 20 & 150 & 50 & 40 \\
\hline O $_{2}$ flow (sccm) & 24 & 0 & 0 & 0 \\
\hline
\end{tabular}

Table 2 : Parameters used in direct current (DC) magnetron sputtering of $\mathrm{SiO}_{2}, \mathrm{Ag}$, $\mathrm{NiCr}$ and $\mathrm{AZO}$. 


\subsection{Silica film recovering process}

With the aim of investigating the thin film structure and avoiding any interference from the substrate signal, a film recovering method was developed to isolate the sputtered silica layer. For this purpose, the previous "reflective mask substrate" including a $50 \mathrm{~nm}$ thick silver layer, was used to receive the coating of silicon dioxide $(1000 \mathrm{~nm})$ (Figure 1). The sacrificial metallic Ag layer is dissolved, by immersion in $6 \mathrm{M}$ reagent nitric acid and the silica films are floated off the solution. An important condition in this process is that the silica film must have an excellent chemical durability to tolerate acid treatments. Due to its high Si-O bond energy (4.5 eV) [58], silicate materials are known to be resistant to chemical attack [59] and therefore satisfy the above condition. As shown in Figure 1, after the silver-AZO acid dissolution, the nitric solution with pieces of floated silica is decanted and the major part of the acid liquid is removed. The flakes and acid mixture were washed several times with deionized water to remove all traces of nitric acid and dried in ambient air more than 12 hours after removal of the maximum residual water. The pieces of recovered silica film have different sizes ranging from approximately 1 to $3 \mathrm{~mm}$, with an estimated thickness of $1000 \mathrm{~nm}$. With this process, approximately $75 \%$ of the deposited material was recovered. This latter was used for the Raman analysis. Crushed powders were prepared for XRD analysis.

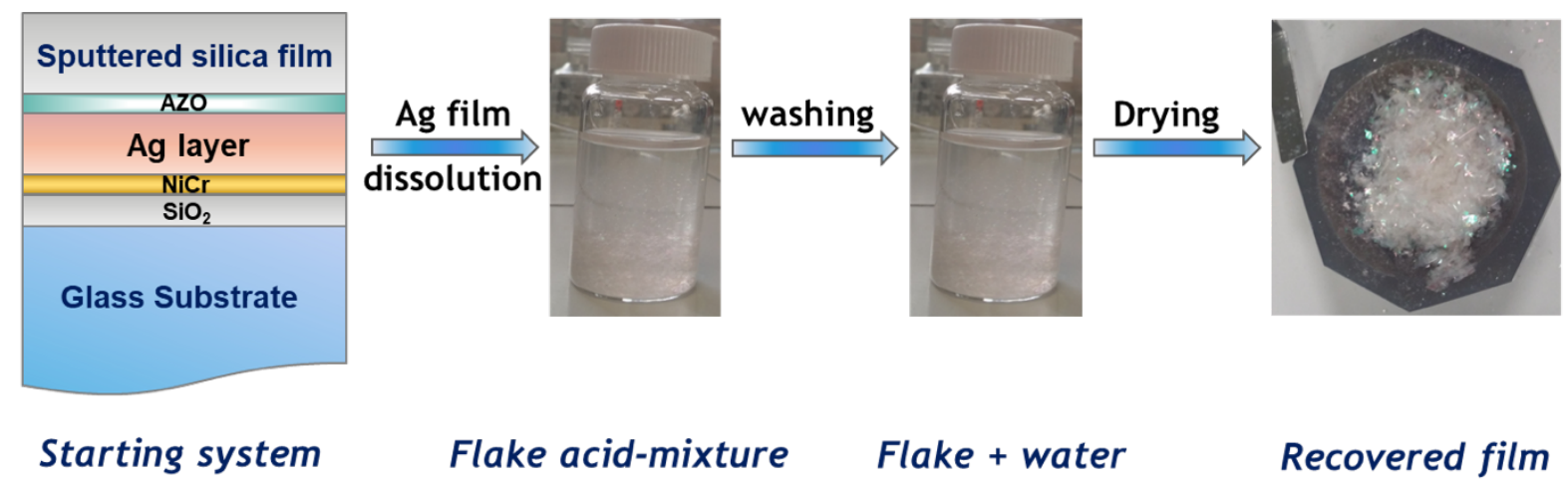

Figure 1: Steps for the recovering of the sputtered silica film by nitric acid attack of a sacrificial silver layer.

\section{Characterization of silica films}

\subsection{In-depth composition}

To control the composition and the depth homogeneity of the sputtered silica film, ToF-SIMS (Time-of-Flight Secondary Ion Mass Spectrometry) characterization was carried out using a 
ION-TOF instrument (GmbH, Munster, Germany) that enables the monitoring of the composition and the spatial evolution of several elements within both the coating and the bulk glass substrate by depth-resolved measurements. This analysis was performed using an alternated sputtering for sample erosion and for sample measurement. A $25 \mathrm{keV}$ pulsed $\mathrm{Bi}^{+}$ ion beam, generated by a liquid metal ion gun, was used for the analysis. The probed area was $100 \times 100 \mu \mathrm{m}^{2}$ at the center of the sputter crater $400 \times 400 \mu \mathrm{m}^{2}$ performed by the Gas Cluster Source generating $20 \mathrm{KeV}$ oxygen cluster $\left(\mathrm{O}_{2}\right)$ of 1500 atoms. The use of this source gives the possibility to reduce both surface charging and the artifacts due to alkali ion migration [60] [61] in comparison to the traditional oxygen and cesium ion sputtering sources. Furthermore, an additional electron flood gun was used in order to neutralize the surface potential during acquisition. Positive monoatomic ions were collected by ToF mass spectrometer for which the mass resolution $(\Delta \mathrm{m} / \mathrm{m})$ is about 6000 .

\subsection{Thickness, density and amorphicity evaluation}

Films thicknesses (100-1000 nm) were measured with stylus profilometry (Dektak XT, Bruker) using an edge created by partially masking the clean glass slide before deposition. Once the film is deposited, the mask, along with the overlaying film, was removed with a cotton swab dampened with ethanol. In addition to the profilometry technique, the thickness of a $150 \mathrm{~nm}$ silica film was double-checked by Dektak measurement of ToF-SIMS craters and by X-ray reflectometry analysis. Furthermore, based on the specular reflectivity, the density of the film was also determined.

Finally, the amorphous nature and the trace presence of crystalline impurities of the asdeposited silica film and the recovered one (without the substrate) were examined respectively by grazing incidence X-ray diffraction (GI-XRD) and by classical X-ray diffraction (XRD) in Bragg-Brentano configuration for $\theta / 2 \theta$ scan. Both XRD measurements were performed on a PANalytical X'Pert Pro X-ray diffractometer (Amelo, Netherland) with Cu-Ka radiation ( $\lambda=1.54065 \AA$ ). Contrary to the regular XRD analysis for which the conventional Bragg Brentano configuration was used, the GI-XRD measurements were performed in the grazing incidence geometry to minimize the contribution related to the substrate. The instrument was operated in a step-scan mode with increments of $0.016^{\circ} 2 \theta$ and in the angular range $3^{\circ}<2 \theta<120^{\circ}$. 


\subsection{Structural characterization by Raman spectroscopy}

Raman spectra were recorded in back-scattering geometry using a Renishaw ${ }^{\circledR}$ InVia $^{\mathrm{TM}}$ Qontor $^{\circledast}$ spectrometer with a solid-state green laser $(532 \mathrm{~nm})$ and an initial power of $50 \mathrm{~mW}$. Spectra were recorded with a CCD detector (Peltier cooled charge-coupled device) in confocal configuration with a $\times 100$ objective and grating with 2400 lines per $\mathrm{mm}$. The instrument configuration restrains the analyzed volume to $1 \mu \mathrm{m}^{3}$ in case of silica based material and allows a spectral resolution of $1.2 \mathrm{~cm}^{-1}$. The spectra were recorded in the range from 100 to $1300 \mathrm{~cm}^{-1}$ and corrected by removing cosmic rays using the Nearest Neighbor algorithm. Baseline correction consisted of subtracting the minimum of the spectra over all the spectral region. Finally, all spectra were normalized to unit area over the same spectral range. To improve the signal-to-noise ratio of Raman acquisitions in slice mode, the spectra were denoised by PCA treatment, used as a noise filter.

Raman analysis was carried out on the three previously described systems (section 2): (a) recovered silica film, (b) "reflective mask substrate" + silica film and (c) glass substrate + silica film. A summary of the different analyzed samples and their Raman acquisition parameters are gathered in Table 3. The acquisition mode and time have been adapted to the different samples. To obtain a representative signal for the pieces of recovered silica film, three spectra measured at three different areas have been averaged. For the silica film on reflective mask substrate, Raman mapping scans were recorded to verify the spectral homogeneity of the sample and the spectra average is retained. For a consistent Raman collection volume, an autofocus device (LiveTrack) was used to continually adjust the height of the motorized microscope stage to maintain perfect focus during scanning. Finally, in order to optimize the separation of the Raman response of thin films deposited directly on a glass substrate using NMF regression, high-resolution Raman "slice" (along $X$ and $Z$ axes) mappings were carried out by changing the focused focal plane along $Z$ (depth) with a step of $0.1 \mu \mathrm{m}$ and along $X$ (lateral) with a step of $1 \mu \mathrm{m}$. Figure 2 illustrates the slice profile measurements of this system that was acquired from $-10 \mu \mathrm{m}$ (within the substrate) to $3 \mu \mathrm{m}$ (in the air above the film) with $0 \mu \mathrm{m}$ corresponding to the estimate of the film-air interface. The latter was determined by focusing on the sample surface through the microscope objective. For each focused depth point, a mapping along a horizontal line (X-axis) along $80 \mu \mathrm{m}$ was acquired to evaluate the film homogeneity. Spectral acquisition time of 5 seconds offers a good compromise between a 
sufficiently high resolution and total acquisition time. The collected "slice" mapping presents a data set of 10610 spectra.

\begin{tabular}{|c|c|c|c|}
\hline Factors Samples & $\begin{array}{c}\text { Glass substrate + } \\
\text { silica film }\end{array}$ & $\begin{array}{c}\text { Reflective mask } \\
\text { substrate }\end{array}$ & $\begin{array}{l}\text { Pieces of the } \\
\text { recovered silica film }\end{array}$ \\
\hline Substrate & Soda-lime glass & 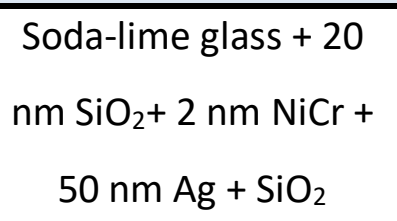 & No substrate \\
\hline $\begin{array}{l}\text { Silica films thickness } \\
\text { (nm) }\end{array}$ & $100-1000 \mathrm{~nm}$ & $100-1000 \mathrm{~nm}$ & $1000 \mathrm{~nm}$ \\
\hline Raman mode & Slice & Mapping & Simple acquisition \\
\hline $\begin{array}{c}\text { Raman exposure time of } \\
\text { one acquisition (s) }\end{array}$ & 6 & 100 & 100 \\
\hline Total acquisition time & 15 hours & 2 hours & 300 seconds \\
\hline
\end{tabular}

Table 3: Summary of the different samples and Raman modes characterization.

Silica film

Thickness $=200 \mathrm{~nm}-1 \mu \mathrm{m}$

Glass substrate

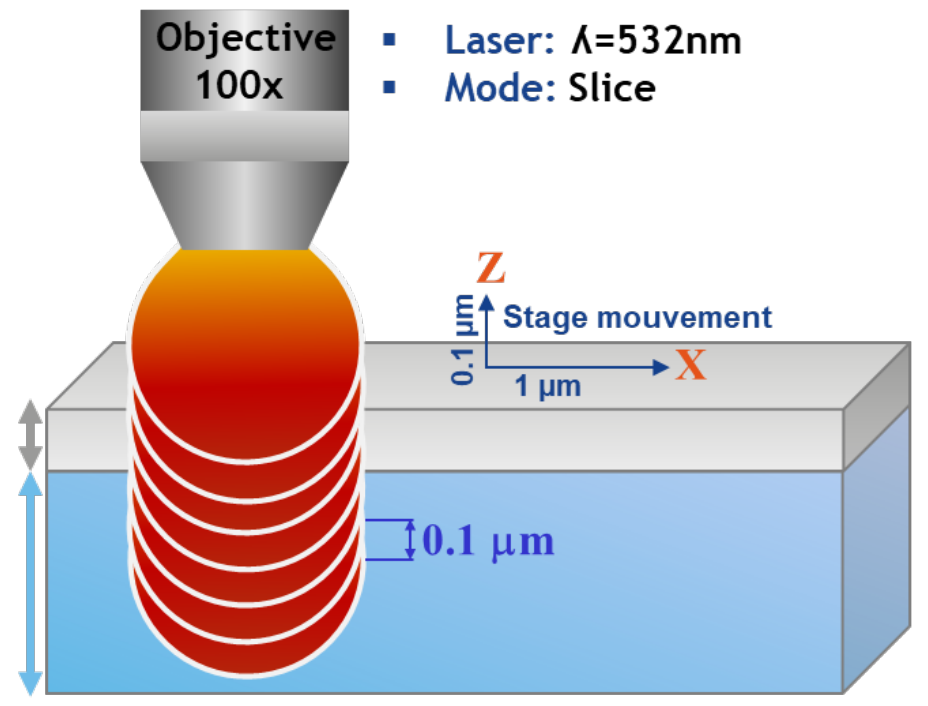

Figure 2: Slice profile acquisition on amorphous silica film deposited on a glass substrate. The laser is focused on different focal planes ( $Z)$, from $3 \mu \mathrm{m}$ above the film surface $(Z=0 \mu \mathrm{m})$ to $-10 \mu \mathrm{m}$ below the surface. 


\section{Results}

\subsection{ToF-SIMS analysis}

In order to check the composition, and more precisely, the presence of impurities within the sputtered silica film, the in-depth composition of the as-deposited film (150 nm) on a sodalime glass was evaluated by ToF-SIMS. Figure 3 presents the resulting SIMS profile of several elements (isotopes) of interest present within the glass substrate and the layer (i.e.: ${ }^{28} \mathrm{Si}^{+}$, ${ }^{23} \mathrm{Na}^{+},{ }^{40} \mathrm{Ca}^{+},{ }^{24} \mathrm{Mg}^{+},{ }^{39} \mathrm{~K}^{+},{ }^{27} \mathrm{Al}^{+},{ }^{120} \mathrm{Sn}^{+}$). The used glass substrate (Planiclear ${ }^{\circledR}$ ) is produced by the float production process and leads to an enrichment of tin at the surface of the so-called bath side [62]. However, the extreme glass surface of the opposite side (called atmospheric side) on which the different layers were deposited, contains also traces of tin, as it is shown in Figure 3 (black signal). The depth calibration can be performed by calculating the depths of two different Tof-SIMS craters. The first one stopped at the glass/layer interface determined by the maximum of ${ }^{120} \mathrm{Sn}^{+}$signal. The second crater was stopped deeper inside the substrate. As shown in Figure 3, the determined thickness of the silica layer is around $150 \mathrm{~nm}$, which is in good agreement with the one measured by stylus profilometry (Dektak). ToF-SIMS method is a quantitative technique. However, due to the ionization yields that are matrix dependent, quantification implies, first, signal calibration. Herein, only the profiles of the raw signals of elements of interest were extracted in order to control the film purity [60]. This analysis reveals that along the depth profile the film contains only silicon, except some small $\mathrm{Al}$ contamination (around $0.4 \mathrm{wt} \% \mathrm{Al}_{2} \mathrm{O}_{3}$ ) from the $\mathrm{Si}$ target and $\mathrm{Na}$ traces on the surface. This implies the absence of any chemical interaction between the glass substrate and the silica film. The results of ToF-SIMS analysis demonstrate a good purity and homogeneity of such a layer. 


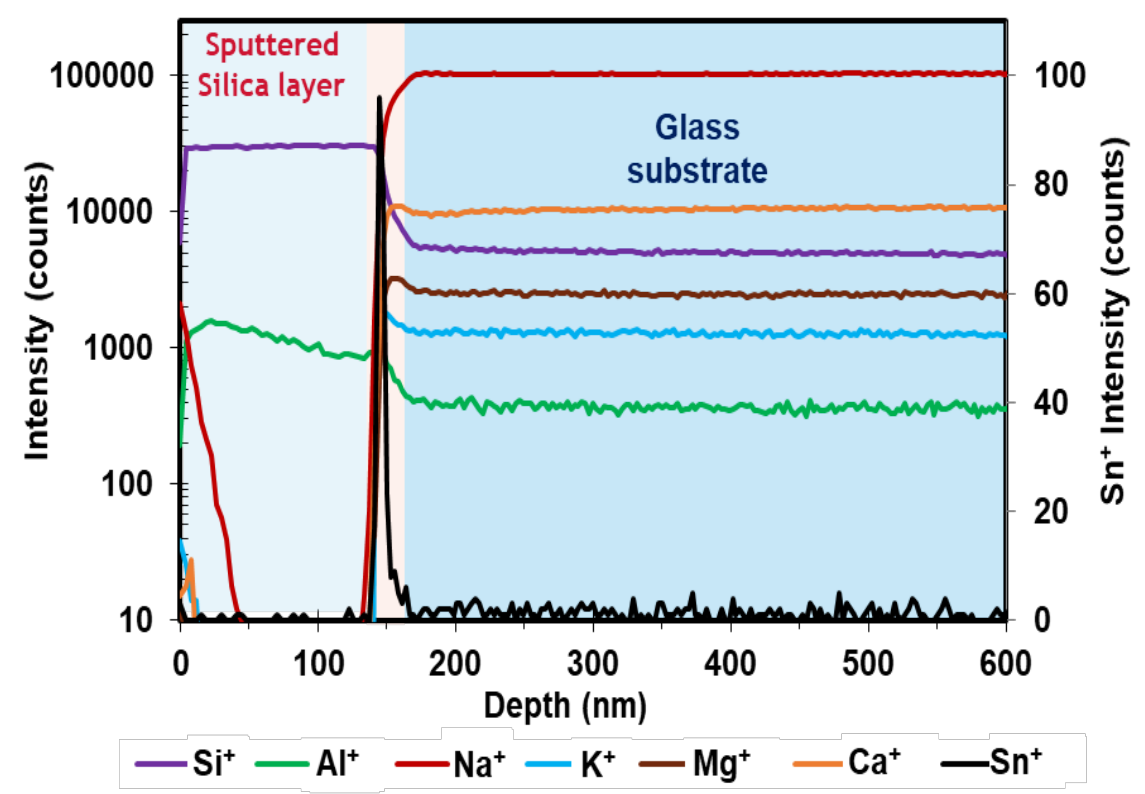

Figure 3: ToF-SIMS depth profile of a glass substrate coated with a sputtered silica film of $150 \mathrm{~nm}$ thickness. The right vertical axis is the intensity values of tin ions (black curve). The left vertical axis represents the intensity of other cations $(\mathrm{Si}+, \mathrm{Al}+, \mathrm{Na}+, \mathrm{K}+, \mathrm{Mg}+, \mathrm{Ca}+)$.

\subsection{X-ray reflectometry and Grazing Incidence X-Ray Diffraction}

Figure 4 shows the obtained reflectivity data for a $150 \mathrm{~nm}$ thick sputtered silica film deposited on the glass substrate with the corresponding simulated curve, using the electron density, the interface roughness and the film thickness as fit parameters. The good correlation between the experimental and the fitted curves indicates that the results should be robust: the estimation of the silica layer thickness is $148 \mathrm{~nm}$, which is in good agreement with both results reported by stylus profilometry (Dektak) and ToF-SIMS. Furthermore, assuming that the layer composition is $\mathrm{SiO}_{2}$, the film density, estimated from the total reflection evaluation, is equal to $2.35 \mathrm{~g} \mathrm{~cm}^{-3}$. 


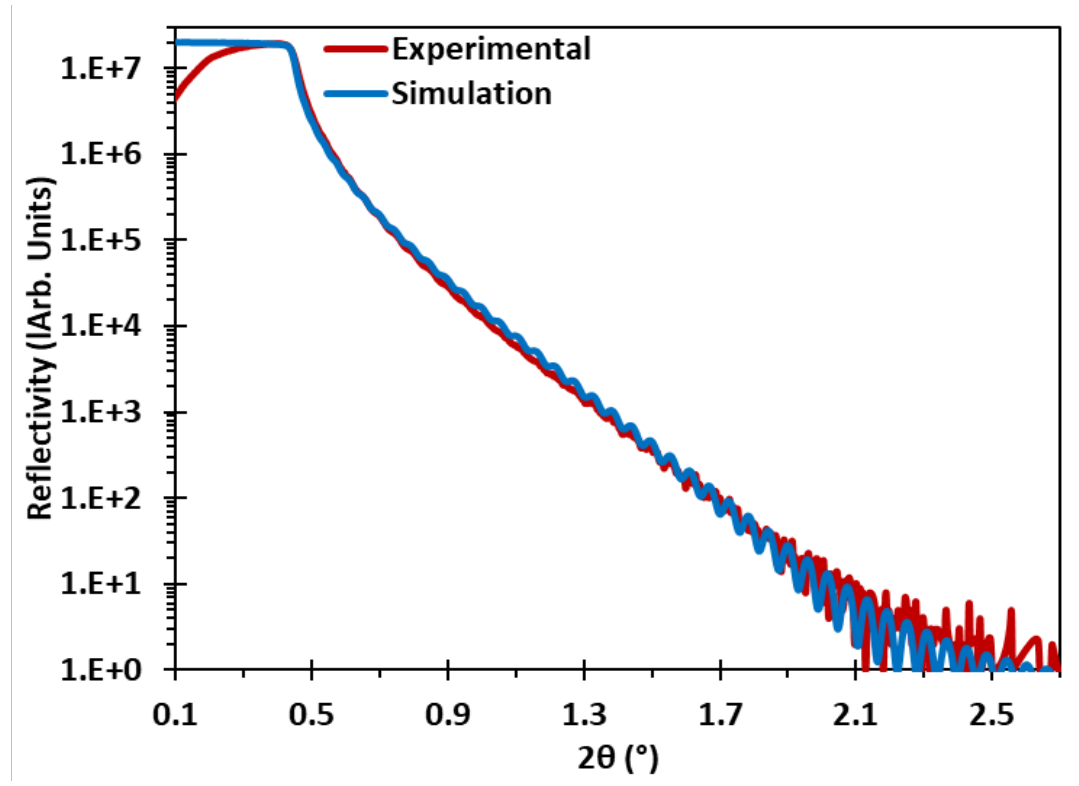

Figure 4: Experimental and simulated X-ray reflectometry data for a silica film deposited on a glass substrate.

The amorphous nature of the sputtered silica film has been examined by means of GI-XRD measurements on a silica film of $1000 \mathrm{~nm}$ thickness deposited on a soda-lime silicate glass and by means of $\theta-2 \theta \times R D$ measurements on a recovered film, to ensure that the recovery process described in section 2.2 does not affect the structural properties of the layer. As shown in Figure 5, both XRD patterns are consistent with an amorphous signature, as revealed by the broad feature at $2 \theta \approx 26^{\circ}$ that is characteristic of a diffuse scattering from a disordered atomic structure. The absence of any sharp Bragg peaks indicates a lack of crystalline order. However, a low intensity peak at $2 \theta=38^{\circ}$ is detected in the XRD pattern of the recovered film that can be attributed to (111) plane of pure silver (JCPDS file No. 04-0783). However, the other lattice planes (200), (220), (311) and (222) of a face-centered cubic (fcc) structure of silver were not detected contrary to the as-deposited Ag layer. This feature indicates a small residual trace of silver from the sacrificial sublayer. 


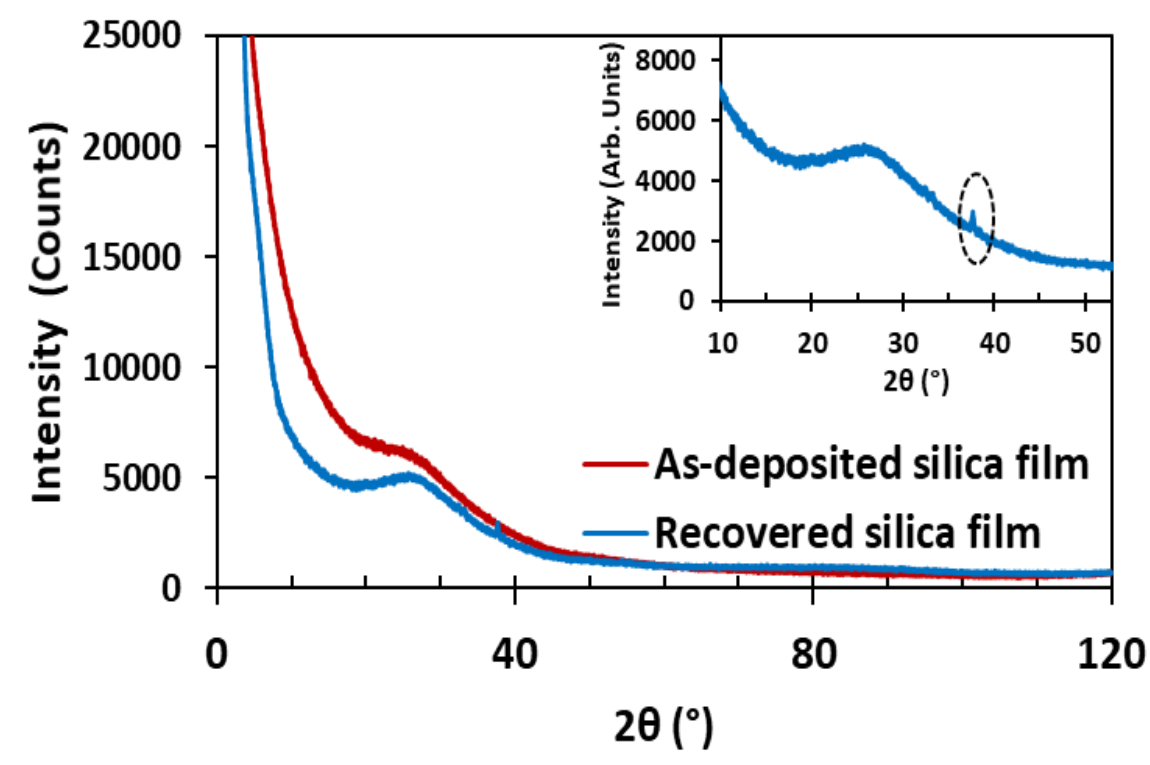

Figure 5: GI-XRD diffractogram of as-deposited silica film $(1000 \mathrm{~nm})$ on a glass substrate (red curve) and XRD $(\theta / 2 \theta$ scan) pattern of the recovered silica coating (blue curve). The insert shows the small Bragg peaks due to a residual signal of the crystalline Ag sacrificial layer.

\subsection{Raman spectroscopy}

Raman analysis were carried out both on (a) the recovered silica film and on (b) the $600 \mathrm{~nm}$ thick silica coating deposited on the reflective mask substrate. In accordance with previous observations [63]-[22]- [24], Figure 6 shows the typical bands identified in the literature for v$\mathrm{SiO}_{2}$ (red spectra) but with different details (relative bands intensities and positions). First, the broad intense rocking-band ( $R$-band) at around $475 \pm 2 \mathrm{~cm}^{-1}$, is associated to bending motions of $\mathrm{Si}-\mathrm{O}-\mathrm{Si}$ bonds in large $n$-membered silicate rings $(n \geq 5)$. Contrary to $\mathrm{v}-\mathrm{SiO}_{2}$ glass, this band shows a pronounced shift to higher wavenumbers in the sputtered silica film. The peaks at $490 \pm 1 \mathrm{~cm}^{-1}$ and $611 \pm 1 \mathrm{~cm}^{-1}$ are known as D1 and D2 lines and are assigned to four- and three-membered rings, respectively [22]-[64]. It is obvious that in our case, the D2 intensity is much higher than the one observed in $\mathrm{V}^{-\mathrm{SiO}_{2}}$. The $810 \pm 2 \mathrm{~cm}^{-1}$ band is related to the $\mathrm{Si}-\mathrm{O}-\mathrm{Si}$ bending modes. The two weak bands at approximately $1060 \pm 3 \mathrm{~cm}^{-1}$ and $1200 \pm 3 \mathrm{~cm}^{-1}$ are attributed to the asymmetric stretching of Si-O-Si bridges in the silica glass network [65]. Figure 6 shows clear and strong similarities between the Raman spectra acquired on the two different thin-film systems, without any additional bands from the substrate. This proves the reliability of the two developed approaches for the extraction of a characteristic Raman signal of the silica film. 


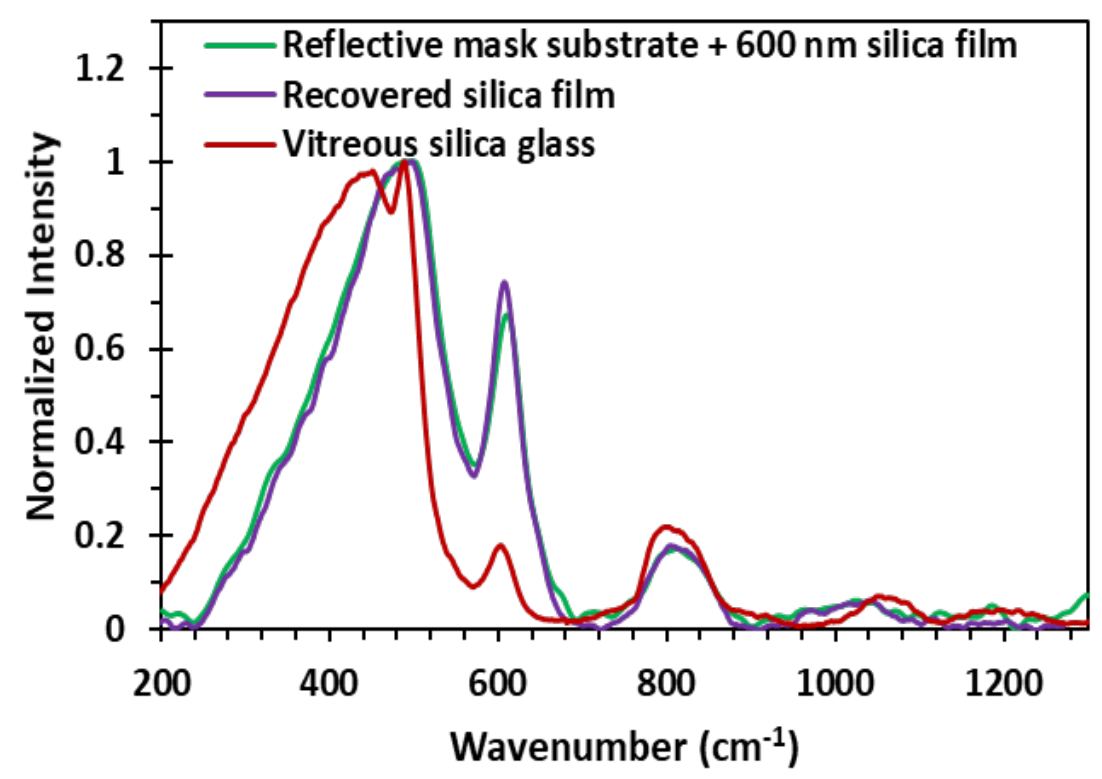

Figure 6: Comparison of Raman spectra obtained on bulk v-SiO ${ }_{2}$, on a recovered silica film and on a silica film deposited on a reflective mask substrate.

As described in section 3.3, confocal Raman microscopy depth profile measurements along Zaxis were also acquired on a $600 \mathrm{~nm}$ thick sputtered silica film deposited on a glass substrate from $-10 \mu \mathrm{m}$ to $3 \mu \mathrm{m}$ with a step of $0.1 \mu \mathrm{m}$ (Figure 2). Figure 7.a presents the denoised Raman spectrum obtained along the substrate and the silica coating. The noise part of the raw data was removed by PCA treatment used as a noise filter. Note that the analyzed film thickness is smaller than the spatial volumetric resolution $\left(\sim 1 \mu \mathrm{m}^{3}\right)$ of the Raman laser.

As expected, the Raman signal evolves along the depth profile since the signatures of the thin film and of the glass substrate are both superimposed with a different ratio depending on the probe depth. For comparison, the Raman spectra of a bare glass substrate is shown in Figure 7.c, exhibiting the typical features of silicate glasses [34]-[35]. The broad band between 300 and $700 \mathrm{~cm}^{-1}$ is associated with the bending modes of $\mathrm{SiO}_{4}$ tetrahedra. The small band at 800 $\mathrm{cm}^{-1}$ is attributed to O-Si-O symmetric stretching. The broad band between $900-1300 \mathrm{~cm}^{-1}$ are associated with stretching modes of $\mathrm{SiO}_{4}$ tetrahedra due to silicon motions involving various $\mathrm{Q}^{\mathrm{n}}$ species ( $n$ is the number of bridging oxygen around a tetrahedrally coordinated silicon atom).

The main features of the depth profile measurements shown in Figure 7.a are obviously similar to the glass substrate spectra (Figure 7.c.). This indicates that the depth profile spectra are largely dominated by the contribution coming from the substrate. The weak contribution of 
the silica coating is explained by the film thickness, smaller than the volumetric Raman resolution. This geometry results in spurious integration from the glass substrate signal even when the laser is focused on the film surface.

The main Raman spectra evolution are localized in the upper profile area $(\sim 0.5 \mu \mathrm{m})$ when getting closer to the silica film. These are clearly noticed from the colormap presented in Figure 7.b, emphasizing the variation of the Raman intensity at each wavenumber point. A significant intensity increase of the low Raman band around $520 \mathrm{~cm}^{-1}$ is visible and a lower intensity at high wavenumbers $\left(\sim 1100 \mathrm{~cm}^{-1}\right)$ points out a decrease of the glass substrate contribution.

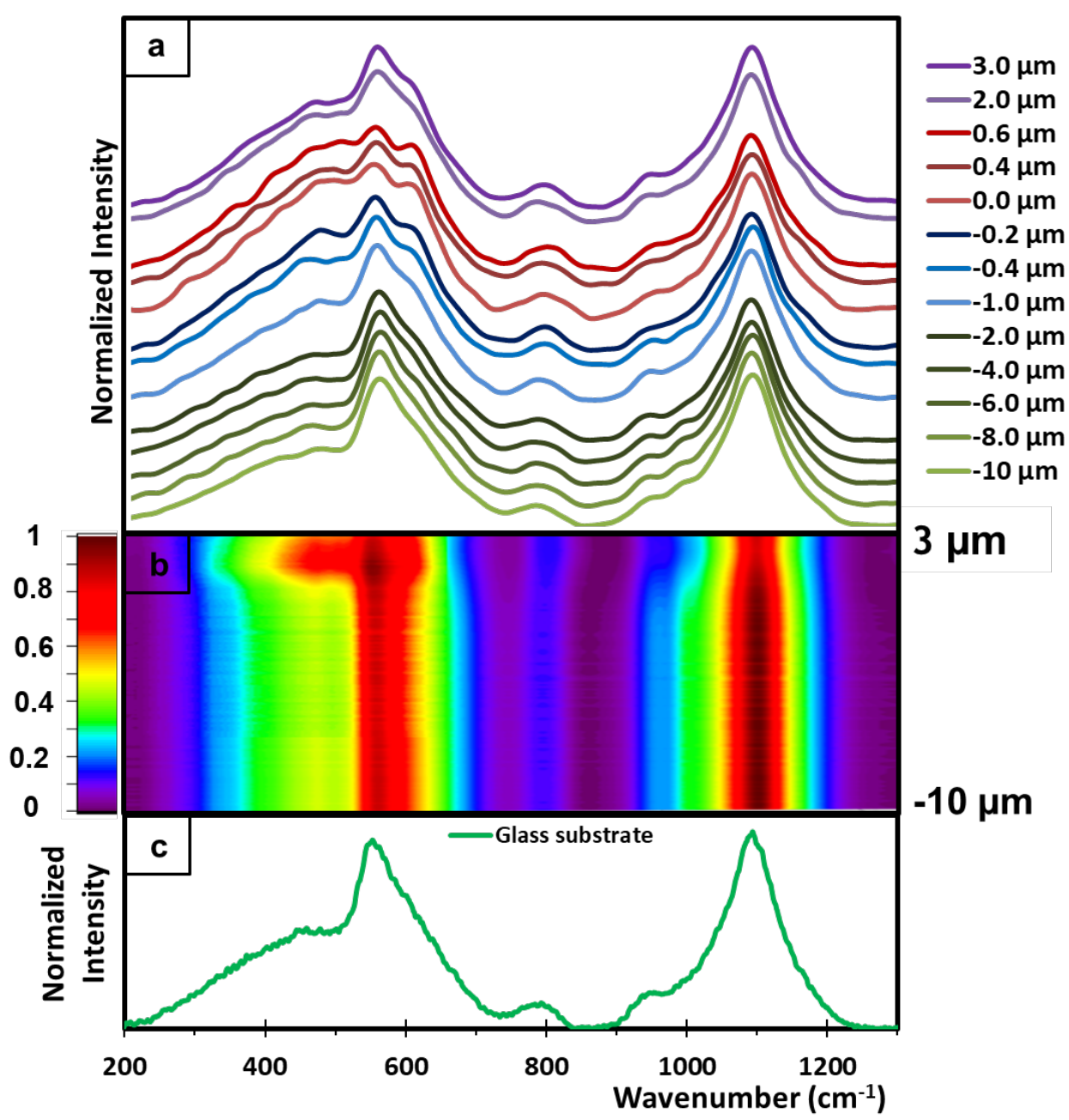

Figure 7: Raman spectra recorded according acquisition conditions described in Figure 2. (a) Selected Raman spectra along a depth profile of a $600 \mathrm{~nm}$ thick silica film deposited on a glass substrate. For visualization purposes, the spectra have been arbitrarily shifted along the ordinate axis (b) the colormap surface projection illustrating the Raman intensity variations for each wavenumber along the depth profile. (c) Raman spectra of the pristine soda-lime silicate glass substrate. 


\section{Discussion}

\subsection{Optimizing the extraction of the Raman signal signature of the sputtered silica film}

As shown in part 4.3, the Raman spectra obtained using a specific reflective mask substrate or a recovered silica film are almost identical, which indicates that they contain the main characteristics of the thin silica film. No contributions from the substrate or other contaminations were observed in the Raman spectra. This proves the absence of any chemical interactions between the silver mask and the deposited silica film (first method) and the preservation of the structural properties during the recovering process of the silica film (second method).

The first approach, based on the use of a reflective mask substrate, seems to be a promising tool for an easy and rapid Raman analysis, as it does not require difficult sample preparation. Furthermore, the reflective mask substrate approach is efficient for Raman characterization of relatively thin silica films, down to $100 \mathrm{~nm}$ thick. However, a reflective coating prevents studying interface phenomena between thin films and glass substrate, like chemical diffusion, that may occur during thermal treatments or even during film deposition in industrial processes.

The advantage of the silica film delamination method is the recovery of sufficient silica film material without the substrate. This material can be used for further structural analysis like NMR and diffraction. Unfortunately, this approach has two fundamental drawbacks. First, it is a more time-consuming methodology and it cannot be used for routine analysis. Second, it cannot be extended to all types of films because some materials do not tolerate acid treatment, for example Ag-containing layers.

For some practical applications, the amorphous silica thin film deposited directly onto a substrate material (float glass) is often required. Therefore, we investigated a third methodology for the extraction of silica thin films Raman spectra using depth profile measurements. Given the absence of any chemical interactions between the glass substrate and the silica thin film, as proven by ToF-SIMS results, the acquired Raman spectra on the surface can be described as a weighted linear combination between the signal from the thin film and that from the glass substrate. The most simple method to extract the film Raman signal is thus to subtract the substrate signal that can be acquired from a pristine glass 
multiplied by a (unknown) coefficient. Figure 8.a presents an attempt of the subtraction method carried out on a $600 \mathrm{~nm}$ thick silica film deposited on the glass substrate. Comparing the mixed spectra to the substrate spectra, we can notice that there are slight differences indicating the contribution of the thin film signal. However, a simple subtraction (blue spectra) does not give a signal similar to that expected for a silica film (Figure 6). Therefore, a $600 \mathrm{~nm}$ film thickness is not sufficient to extract reliable structural features of the silica film.
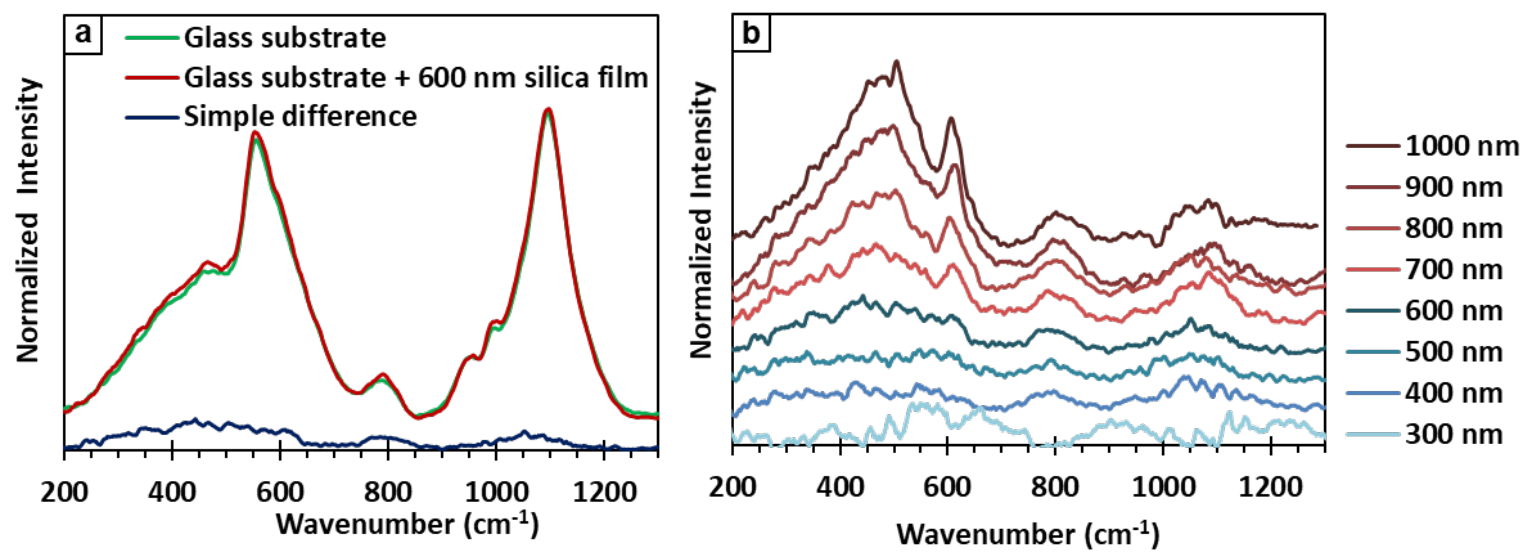

Figure 8: (a) Raman spectra for the glass substrate and for the glass substrate $+600 \mathrm{~nm}$ silica film and the difference spectra (blue) between the two signals. (b) Difference Raman spectra obtained after subtraction of the bare glass substrate signal for a series of different silica film thicknesses. The spectra have been arbitrarily shifted along the ordinate axis for clarity.

As the cross-section is directly proportional to the scattering volume, we tried the same method with different subtraction coefficients for thicker films (Figure 8.b). It is obvious that for thicknesses between $300 \mathrm{~nm}$ to $600 \mathrm{~nm}$, no discernible signal from the thin film is detected. From $700 \mathrm{~nm}$ thickness, some Raman features from the silica film can be extracted. The quality of the extracted signal and the features evolve as the film thickness increases. It remains thereby difficult to distinguish a priori from which thickness one can rely on the extracted signal. Furthermore, the subtraction of the dominant substrate signal is vulnerable to the acquisition noise and the choice of the baseline subtraction [50]. This is particularly important in the present work as the silica films have very weak Raman intensities (due to the low cross-section of the silica film and its small thickness) that are already dominated by noise and that overlap with the likewise broad signal of the glass substrate. The error accumulation due to the noise and the baseline subtraction can result in a significant loss of information and hinder dramatically the interpretation, even in the best experimental configuration. In summary, the subtraction method of an arbitrary fraction of the bare glass substrate signal is 
an uncertain and inaccurate analysis protocol that was deemed not suitable for the purpose of the present work. Therefore, we implemented alternative approaches that must be favored.

In this investigation, the NMF technique was applied on the depth Raman profiles (Figure 7). The acquired Raman spectra along a depth profile can be described as a weighted linear combination of two Partial Raman Spectra (PRS) corresponding to the substrate and the film. The contribution of each PRS in the spectra can be varied for the different focus points along the depth profile. Enough statistical Raman spectra points (10610 in the present investigation) are required to apply the deconvolution procedure based on NMF technique. In practice, NMF consists in decomposing the spectra datasets $(\mathrm{Y})$ along a depth profile to obtain a unique set of individual PRS:

$$
\boldsymbol{Y}=\sum_{i}(\boldsymbol{H} X)_{i}+\varepsilon=\left(\boldsymbol{H}_{i}^{\text {substrate }} \boldsymbol{X}^{\text {substrate }}+\boldsymbol{H}_{i}^{\text {film }} \boldsymbol{X}^{\text {film }}\right)+\varepsilon
$$

The $\mathrm{H}$ matrix of weights contains the $\mathrm{H}_{\mathrm{i}}$ contribution of each PRS defining the matrix $\mathrm{X}$. The sum is over the measured point $i$ and $\varepsilon$ is a residual error. The main advantage of this approach is to avoid any a priori hypothesis on the true shape or position of each component. The method is designed with a minimum number of arbitrary parameters. NMF procedure consists of minimization of the cost function $\sum_{i}\left(Y_{i}-(H X)_{i}\right)^{2}$ with the complementary condition that both $\mathrm{H}$ and $\mathrm{X}$ matrices contain non-negative values. The NMF code is adapted from a Python implementation described in a previous paper [57]. Using NMF regression, two components, presented in Figure 9, can be determined from the decomposition of the experimental Raman data set. The Raman spectra of each component show very distinct features (Figure 9.a) and they have complementary weights along the depth profile (Figure 9.b). The evolution of the associated weights reveals that component 1 is the dominant one, especially in the region of negative $Z$ values where component 2 has a null contribution. Inversely, a submicronic region around $Z=0 \mu \mathrm{m}$ value presents an increasing fraction of component 2 , with a maximum reaching $20 \%$, and a decreasing fraction of component 1 . The observed scores evolution of the first and second NMF components suggests that they correspond to the signature of the glass substrate and the silica layer, respectively. Note that further increase of component 1 fraction above $Z=1.5 \mu \mathrm{m}$ can correspond to out-of-focus contributions that are well known [66] to occur when focusing in air above the sample surface. 

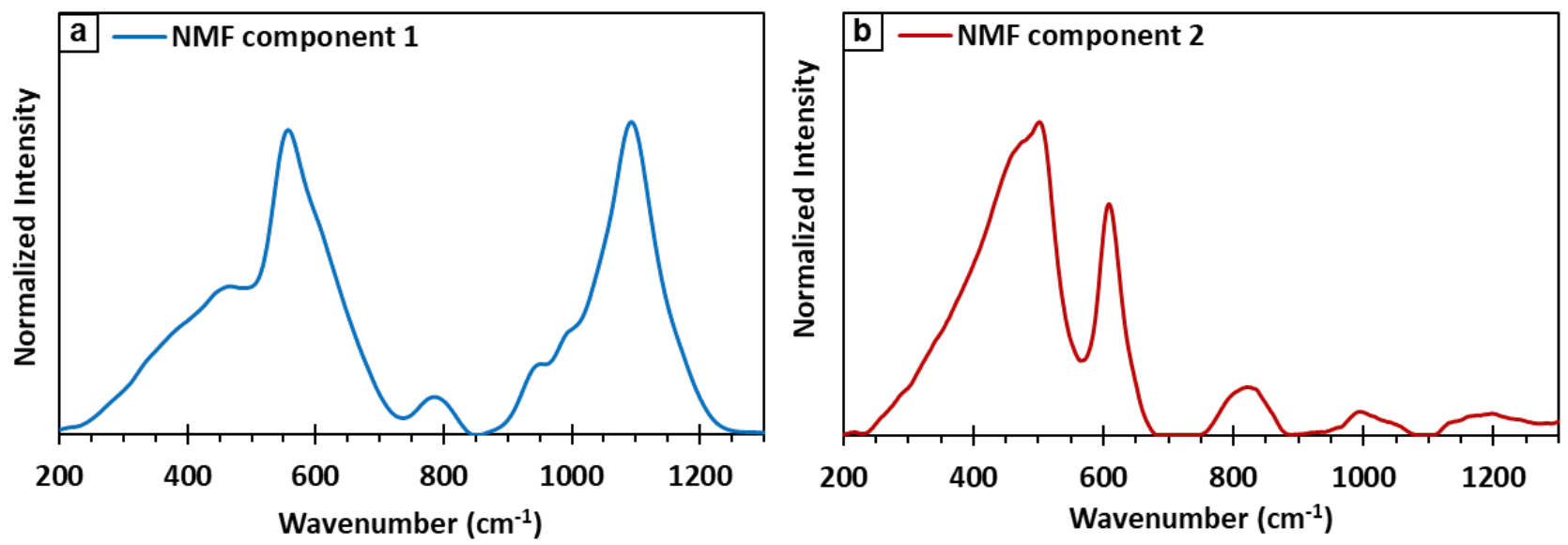

C
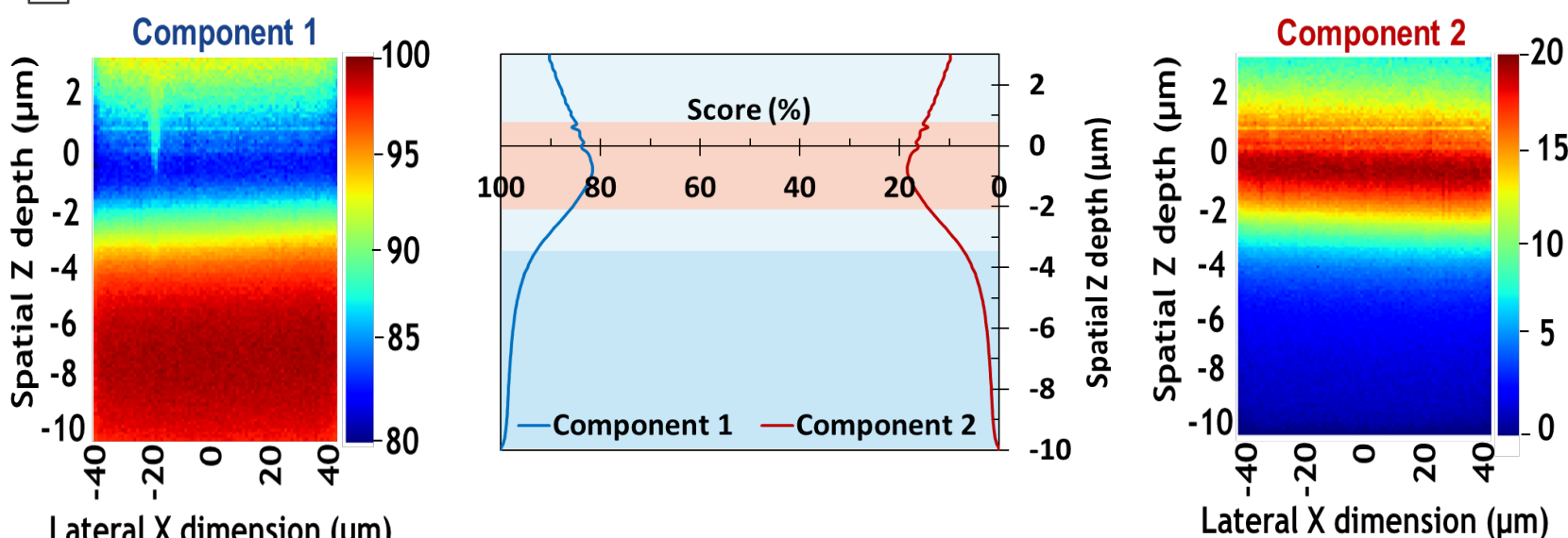

Lateral $\mathbf{X}$ dimension (um)

Lateral $\mathrm{X}$ dimension $(\mu \mathrm{m})$

Figure 9: NMF analysis: (a) First and (b) second NMF components extracted from the Raman spectra data set shown in Figure 7 for the stack system (glass substrate $+600 \mathrm{~nm}$ thick silica film) and (c) their associated components scores along the depth profile.

In order to give evidence to this attribution, Figure 10.a compares the spectra corresponding to the first NMF component with the Raman spectra of the glass substrate (Figure 8). There is a remarkable agreement between the two signals, confirming that component 1 can be unambiguously attributed to the glass substrate. To validate the efficiency of NMF technique for the extraction of the film Raman signal, Figure 10.b compares the NMF component 2 with the Raman spectra of silica film determined previously in figure 6 . The three spectra from the different approaches are very similar. This overall excellent agreement confirms that component 2 can be confidently attributed to the silica layer and that the NMF decomposition 
gives an accurate extraction of the Raman signal for the silica film. However, a slight variation of D2 band area was observed. This can be associated to a small difference in the plastic shear strain, probably affected by the surface substrate nature, which highly influences the proportion of the three-membered rings [67]-[68]-[69]. Considering the literature, the impact of shear deformation will be discussed further in the structural interpretation part of the silica film.
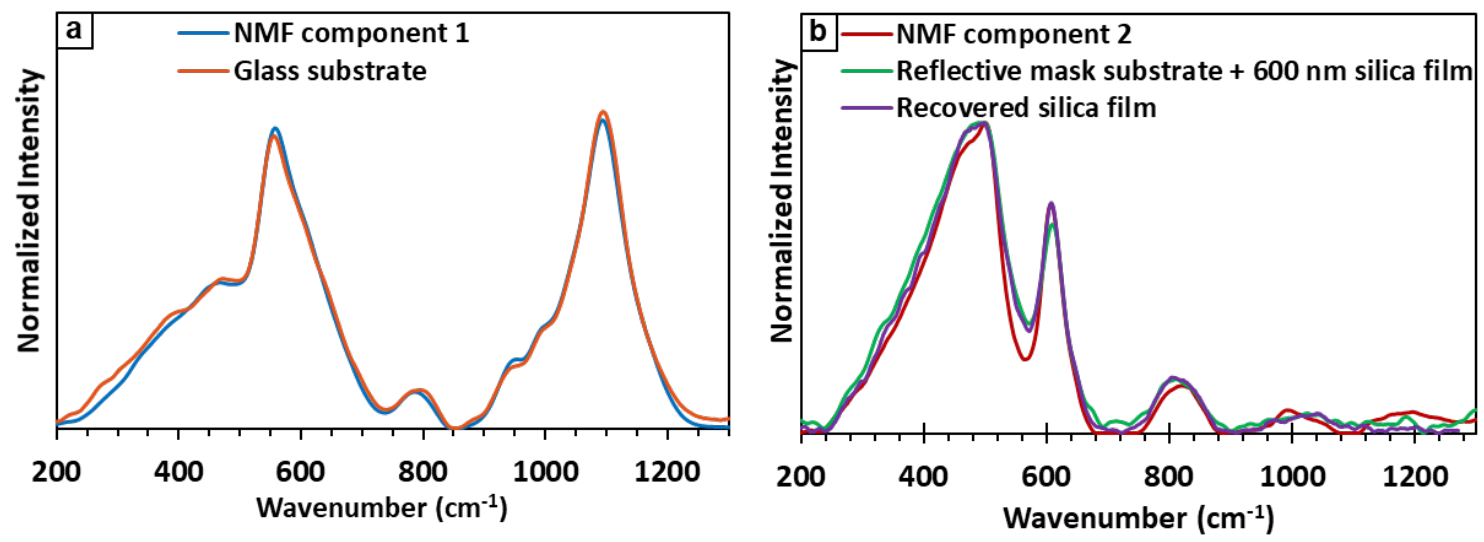

Figure 10: Attribution of (a) the first NMF component to the signature of the glass substrate and (b) the second NMF component to the signature of the sputtered silica film.

For an extensive test of the performances of the NMF methodology, a series of silica films with thicknesses from $100 \mathrm{~nm}$ to $1000 \mathrm{~nm}$ was deposited on a glass substrate and confocal Raman microscopy depth profiles were acquired before NMF analysis. This investigation allows us to discuss the minimal silica film thickness necessary to extract reliable NMF components. Figure 11 presents the NMF component corresponding to the silica film for different film thicknesses. For a reliable interpretation, we will focus on the entire spectral region between $100-1300 \mathrm{~cm}^{-}$ 1. Excepting the $100 \mathrm{~nm}$ thick silica film, strong similarities exist between the extracted components and the experimental Raman spectra of sputtered silica film. The determined NMF signal from the $100 \mathrm{~nm}$ thick film presents a large envelope in the high-frequency region between $1000-1300 \mathrm{~cm}^{-1}$. This band is the signature of a parasitic substrate contribution that presents an intense band between $1000-1300 \mathrm{~cm}^{-1}$ (Figure 7.c) corresponding to various $Q^{n}$ species in the silicate network. The apparition of this band can be explained by the decrease of the film contribution in the illumination volume (excited volume) of the Raman laser with the decrease of the layer thickness. However, it does not affect the main silica film Raman 
features at low frequencies. Therefore, we can conclude that down to a thickness of $200 \mathrm{~nm}$, NMF decomposition allows accurate and workable extraction of the silica film Raman signal, with no spurious substrate contributions.

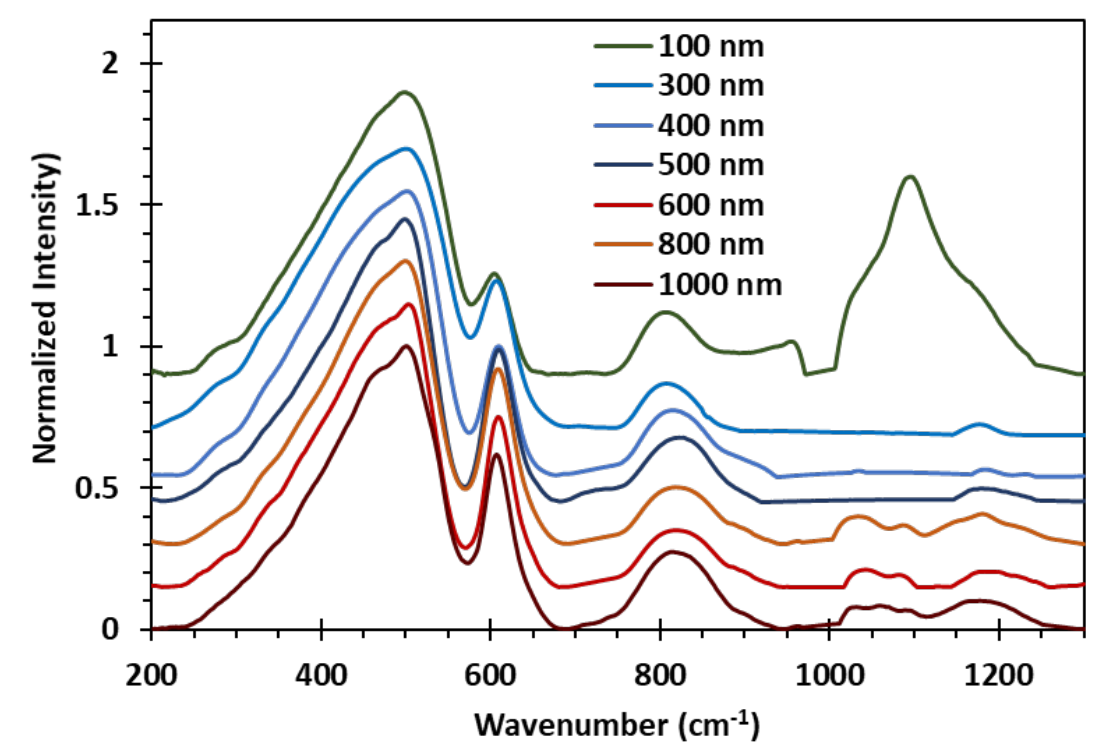

Figure 11: Extracted NMF components corresponding to the Raman signal of silica films with different thicknesses. The spectra have been arbitrarily shifted along the ordinate axis for clarity.

Compared to some other numerical tools, like for example the principal component analysis (PCA), NMF presents some clear advantages. Probably the most important one is that NMF components may usually be directly attributed to some vibrational modes of the sample materials, whereas the PCA components are usually much more difficult to interpret. Indeed, NMF prevents the negative components and scores from occurring, which avoids contradicting physical reality. Then, the derived NMF components can be easily interpretable [70]-[71]. Furthermore, the NMF technique presents numerous advantages compared to the two other approaches described in this work: films recovery and use of the reflective mask substrate. It is a non-destructive method that excels by its simplicity. A rapid Raman characterization can be done without any sample preparation. Added to that, thanks to this NMF methodology for Raman investigation, relevant avenues are opened. The most promising one is the Raman investigation of interface phenomena, particularly the chemical diffusion, that may occur between the glass substrate and thin films during thermal treatment [10]-[72]. Furthermore, NMF is an interesting tool for other studies like the influence of the substrate 
on the epitaxial structural change of ultra-thin crystalline films [73]. However, despite all these advantages, NMF has some limits. Unfortunately, spectra film noise and its low signal can hinder dramatically the stability of NMF in finding the correct film component. It can be necessary to introduce complementary components to separate noise from film signal. In this case, it is slightly more ambiguous to determine the exact physical variations of the peaks (amplitude, position and width), as they can be spread through multiple components. This was the case of the $100 \mathrm{~nm}$ thick silica film for which we have used 3 components to extract silicalike spectra with some substrate parasitic contribution at high number wavelengths.

\subsection{Structural understanding of the sputtered silica film}

Thanks to the methodology described above, a reliable structural Raman fingerprint of the recovered silica film is extracted, offering interesting perspectives to gain insights on the structural organization of silica films. In Figure 12, we compare the Raman spectrum of the sputtered silica film to the Raman spectrum of a high pure $(99.59 \%)$ commercial bulk vitreous silica glass (Quartzel ${ }^{\circledR}$ ) having a density of $2.20 \mathrm{~g} \mathrm{~cm}^{-3}$. Drastic differences are clearly observed between these two silica materials prepared by different processes. This reveals that the structure of the sputtered silica film strongly differs from that of a bulk v-SiO ${ }_{2}$.

As clearly shown in Figure 12, the most significant change concerns the Raman bands between 200-750 $\mathrm{cm}^{-1}$. The R-band, associated to the bending motion of Si-O-Si bonds, becomes narrower and shifts toward higher wavenumbers $\left(475 \pm 2 \mathrm{~cm}^{-1}\right)$ within the sputtered silica film. The change in position and width of this band is directly connected to an evolution of the SiO-Si network angle $(\theta)$ and its distribution [74]-[24] highlighting a transformation of the short range order. The 'defect' lines D1, initially located at $490 \pm 1 \mathrm{~cm}^{-1}$ merges with the R-band and is hardly distinguishable. However, the most notable modification observed in the Raman spectra is the large increase of the D2 line intensity with a slight shift towards higher wavenumber $\left(611 \pm 1 \mathrm{~cm}^{-1}\right)$ and an obvious line broadening. The D2 broadening and shift, visualized in the insert in Figure 12, are hypothesized to be caused by the high constrained three-membered rings [75]-[67]. The average residual stress in the films was assessed by substrate curvature analyses. The curvature, determined by white light interferometer, puts in evidence a compressive stress of $-280 \mathrm{MPa}$ in the film, that can explain the observed D2 shift and broadening. Being a signature of the specificities of the related stress tensor [68], the increase of D2 amplitude highlights the effect of the shear stress that facilitates the 
formation of the small three-membered rings [67]-[68]-[69]. The impact of the shear deformation on the Raman features was confirmed by the simulation of Raman spectra of silica glass under plastic shear [69] and, more recently, from the experimental and simulation works [68] comparing Raman features of densified silica glass obtained under fully and partially hydrostatic process and having similar densification rates. Both studies point out that the increase of the three-fold ring proportion at the expense of larger rings is favored by shear stress, as opposed to hydrostatic compression.

The atomic structural organization revealed by the spectroscopic signatures of the sputtered silica film are induced by two processes: 1 ) densification and 2) shear deformation that both involve three-fold membered ring proportion increase and distortion. These observations prove that the magnetron sputtering is not a purely hydrostatic process but yields shear deformation, similar to the uniaxial micro-pillar compression [68] or to the femtosecond laser irradiation [76].

All these observed modifications are similar to previous results attributed to a densification of the silicate network due to various external constraints: high pressure [23] -[24]-[67], indentation deformation [77], irradiation [28]-[78] or glass thermal history [79]. Therefore, we can conclude that the sputtered silica film is a dense material having a structural organization significantly different to that of bulk $\mathrm{v}-\mathrm{SiO}_{2}$. This densification implies an increase in the number of small-membered-rings, in particular the threefold rings [67] and a decrease of the Si-O-Si intertetrahedral bond angle $\theta$. As it was stated earlier [24] the frequency of the R-band is associated with the distribution of the intertetrahedral angle in the silica network. By leveraging the model proposed by Sen and Thorpe (ST) [80], the average change in $\theta$ can be derived. The ST central force model connects $\mathrm{SiO}_{2}$ vibration frequencies $\left(\omega, \mathrm{cm}^{-1}\right)$ to the bond angle $(\theta)$ and the $\mathrm{Si}-\mathrm{O}$ force constant of the $\mathrm{SiO}_{2}$ network [81]. Following this approach, the Rband shift of $35 \pm 1 \mathrm{~cm}^{-1}$ observed in the Raman spectrum of the as-deposited film corresponds to a decrease of $\theta$ down to $141^{\circ}$ compared to $144^{\circ}$ for $\mathrm{v}-\mathrm{SiO}_{2}$. A small $\theta$ value is related to stressed networks, mostly in dense structures [82].

In addition to the Raman result, X-ray reflectivity measurements support the densification of the sputtered silica film with a higher density of $2.35 \mathrm{~g} . \mathrm{cm}^{-3}$ than the one for bulk $\mathrm{v}-\mathrm{SiO}_{2}$ $\left(2.2 \mathrm{~g} \mathrm{~cm}^{-3}\right)$. This densification can be explained by high energy ions bombardment that yields an increase of the film compactness [83]-[84]. The film densification outcome is consistent with previous studies showing that CVD [85]-[86], IAD [87] and sputtering process [88] yield 
densified silica coatings. Therefore, our approach based on probing the microstructure by spectroscopic tools reveals the densification features of silica films and offers interesting perspectives to better characterize the layer structure.

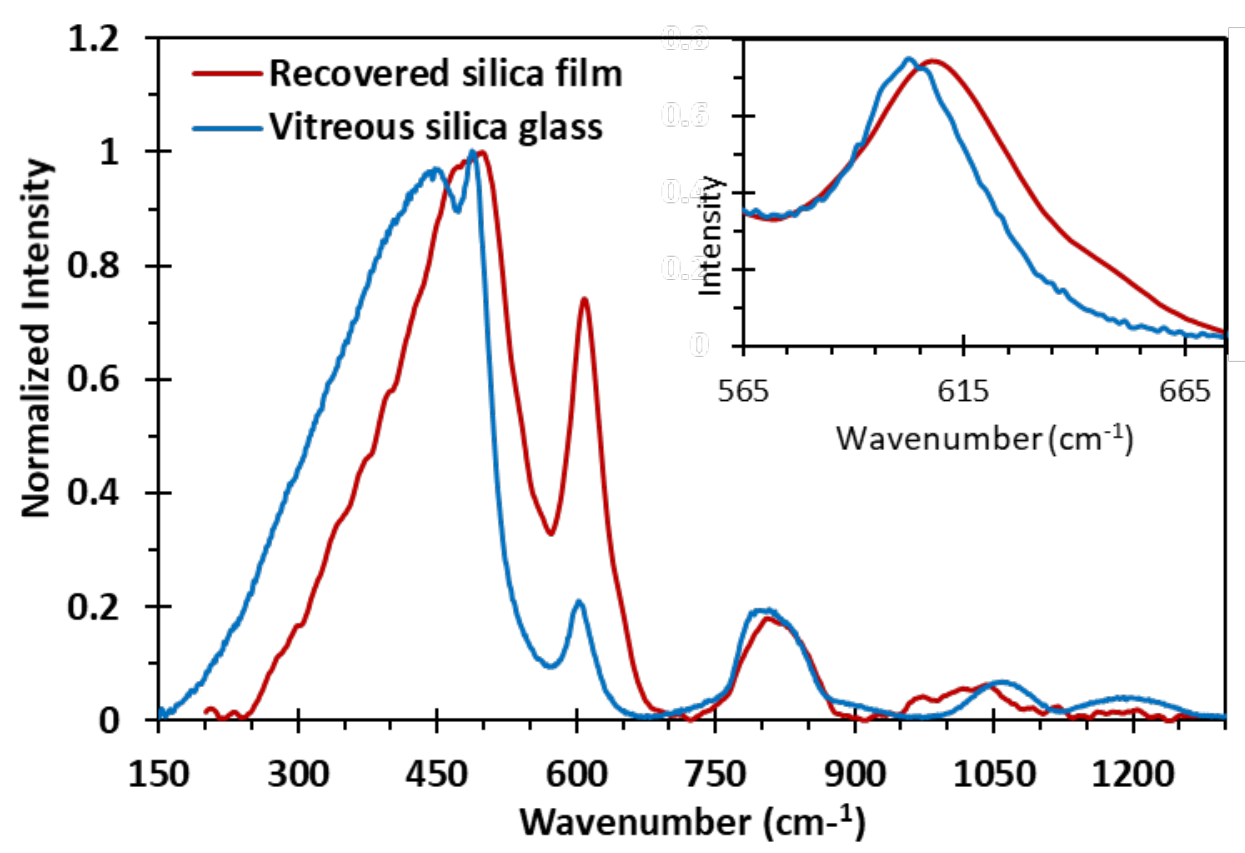

Figure 12: Comparison of the Raman spectra of the as-deposited silica coating to that of the bulk v-SiO ${ }_{2}$. The insert presents the D2 band normalized to its intensity, to emphasize the shifting and broadening of the D2 band.

\section{Conclusion:}

The structural Raman properties of sputtered silica films have been investigated in the present work using three approaches: (a) recovery of the silica film, (b) use of a low-cost substrate mask by deposing a silver reflective coating $(50 \mathrm{~nm})$ on the glass substrate surface and, finally, (c) a multivariate analysis tool based on NMF. Despite all the technical challenges due to the small thickness of the amorphous films and its low cross-section, well-matched results of the extracted Raman signals of the silica film have been obtained, proving the reliability of the proposed techniques. Each of these methods presents different strengths and weaknesses for the problems at hand. The recovery of a thin film requires an extensive sample preparation with thick film deposition $(1000 \mathrm{~nm})$ but opens innovative perspectives for other complementary structural studies, such as diffraction and NMR techniques. Using the Agmirror coatings is highly promising for a rapid Raman characterization even for relatively thin films, down to $100 \mathrm{~nm}$ thickness in the present case of silica films. However, it prevents 
studying the interface phenomena between thin films and glass substrate. In turn, NMF presents many advantages and excels by its simplicity. Its fundamental strength is the rapid characterization of a thin layer ( $\geq 200 \mathrm{~nm}$ ) without any sample preparation. Furthermore, the NMF findings can be extended toward relevant perspectives for the application of Raman spectroscopy on other thin films. One of the perspective opened by this work is the investigation of interface phenomena, particularly chemical diffusion, that may occur between the glass substrate and thin films during thermal treatment. For these applications, given the strengths and weaknesses of each approach, we would suggest a preference towards Raman depth profiles combined with NMF for further extending Raman investigation. Thanks to these developed approaches, interesting structural properties of the sputtered silica film have been brought to light. Structural differences between $\mathrm{v}-\mathrm{SiO}_{2}$ glass and sputtered silica film have been emphasized. We showed that magnetron-sputtering deposition induces a silica film densification with a large shear strain. The resulted sputtered silica film is dense and reorganized in a more homogeneous network in terms of tetrahedral bond angle distribution, due to the reorganization of $\mathrm{SiO}_{4}$ tetrahedra- similar to that previously observed in silica glasses densified under pressure or irradiation. The atomic structural organization is driven by two processes: densification and shear deformation. At the medium distance scale, the network connectivity is expressed by a change in the ring statistics favoring the formation of smaller ones, leading to a dense structure. By using Raman measurements and the ST model, we also highlight the short-range transformation due to the decrease of the $\mathrm{Si}-\mathrm{O}-\mathrm{Si}$ intertetrahedral angles which can be an important mechanism of the network compression.

\section{Acknowledgments}

The authors would like to thank Benoit Baptiste (Sorbonne Université), Sophie Nowak (Université de Paris) and Thierry Cretin (Saint-Gobain Recherche) for fruitful discussions and help with the grazing incidence X-ray diffraction (GI-XRD), X-ray reflectivity and ToF-SIMS measurements, respectively. The work was made possible thanks to financial support from the ANR project "MAGI (ANR-17-CE08-0019)". 


\section{References}

[1] R. Thielsch, A. Gatto, J. Heber, N. Kaiser, A comparative study of the UV optical and structural properties of $\mathrm{SiO} 2, \mathrm{Al} 2 \mathrm{O} 3$, and $\mathrm{HfO} 2$ single layers deposited by reactive evaporation, ionassisted deposition and plasma ion-assisted deposition, Thin Solid Films. 410 (2002) 86-93. https://doi.org/10.1016/S0040-6090(02)00208-0.

[2] C. Martinet, V. Paillard, A. Gagnaire, J. Joseph, Deposition of SiO2 and TiO2 thin films by plasma enhanced chemical vapor deposition for antireflection coating, Journal of Non-Crystalline Solids. 216 (1997) 77-82. https://doi.org/10.1016/S0022-3093(97)00175-0.

[3] J. Sun, J. Miao, High performance MEMS inductors fabricated on localised and planar thick SiO2 layer, Electronics Letters. 41 (2005) 446. https://doi.org/10.1049/el:20050086.

[4] K.T. Rao, S.S. Chauhan, S. Manhas, Sputtered silicon dioxide layers forMEMS applications, in: 2015 National Conference on Recent Advances in Electronics \& Computer Engineering (RAECE), IEEE, Roorkee, India, 2015: pp. 222-227. https://doi.org/10.1109/RAECE.2015.7510194.

[5] M.H. Francombe, ed., Non-crystalline films for device structures, Academic Press, San Diego, 2002.

[6] H. Klauk, M. Halik, U. Zschieschang, G. Schmid, W. Radlik, W. Weber, High-mobility polymer gate dielectric pentacene thin film transistors, Journal of Applied Physics. 92 (2002) 5259-5263. https://doi.org/10.1063/1.1511826.

[7] A.G. Aberle, Surface passivation of crystalline silicon solar cells: a review, Progress in Photovoltaics: Research and Applications. 8 (2000) 473-487. https://doi.org/10.1002/1099159X(200009/10)8:5<473::AID-PIP337>3.0.CO;2-D.

[8] S.V. Ghaisas, O.S. Shinde, R.O. Dusane, N.G. Dhere, Low temperature surface passivation of silicon solar cells, in: 2016 IEEE 43rd Photovoltaic Specialists Conference (PVSC), IEEE, Portland, OR, USA, 2016: pp. 2889-2892. https://doi.org/10.1109/PVSC.2016.7750184.

[9] M.N. Ghazzal, E. Aubry, N. Chaoui, D. Robert, Effect of $\operatorname{SiN}_{x}$ diffusion barrier thickness on the structural properties and photocatalytic activity of $\mathrm{TiO}_{2}$ films obtained by sol-gel dip coating and reactive magnetron sputtering, Beilstein Journal of Nanotechnology. 6 (2015) 2039-2045. https://doi.org/10.3762/bjnano.6.207.

[10] J.-T. Fonné, E. Burov, E. Gouillart, S. Grachev, H. Montigaud, D. Vandembroucq, Aluminumenhanced alkali diffusion from float glass to PVD-sputtered silica thin films, Journal of the American Ceramic Society. 101 (2018) 1516-1525. https://doi.org/10.1111/jace.15340.

[11] P. Galliano, J.J. De Damborenea, M.J. Pascual, A. Durán, Sol-Gel Coatings on 316L Steel for Clinical Applications, Journal of Sol-Gel Science and Technology. 13 (1998) 723-727. https://doi.org/10.1023/A:1008653208083. 
[12] Tuan.H. Pham, Cu.X. Dang, lon assisted deposition of SiO 2 film from silicon, in: C. Amra, N. Kaiser, H.A. Macleod (Eds.), Jena, Germany, 2005: p. 59631U. https://doi.org/10.1117/12.625021.

[13] Taofang Zeng, H. Doumanidis, J. Hebb, D. Brown, Growth of ultrathin silicon dioxide films during rapid-thermal oxidation, in: 9th International Conference on Advanced Thermal Processing of Semiconductors, RTP 2001, RTP, Anchorage, AK, USA, 2001: pp. 287-295. https://doi.org/10.1109/RTP.2001.1013781.

[14] J. Foggiato, Chemical Vapor Deposition of Silicon Dioxide Films, in: K. Seshan, W. Andrew (Eds.), Handbook of Thin Film Deposition Processes and Techniques, Elsevier, 2001: pp. 111-150. https://doi.org/10.1016/B978-081551442-8.50008-0.

[15] A.G. Revesz, H.L. Hughes, The structural aspects of non-crystalline SiO2 films on silicon: a review, Journal of Non-Crystalline Solids. 328 (2003) 48-63. https://doi.org/10.1016/S00223093(03)00467-8.

[16] K. Sekine, Y. Saito, M. Hirayama, T. Ohmi, Highly reliable ultrathin silicon oxide film formation at low temperature by oxygen radical generated in high-density krypton plasma, IEEE Transactions on Electron Devices. 48 (2001) 1550-1555. https://doi.org/10.1109/16.936559.

[17] F. Iacona, G. Ceriola, F. La Via, Structural properties of SiO2 films prepared by plasma-enhanced chemical vapor deposition, Materials Science in Semiconductor Processing. 4 (2001) 43-46. https://doi.org/10.1016/S1369-8001(00)00130-X.

[18] H.-P. Ma, J.-H. Yang, J.-G. Yang, L.-Y. Zhu, W. Huang, G.-J. Yuan, J.-J. Feng, T.-C. Jen, H.-L. Lu, Systematic Study of the SiOx Film with Different Stoichiometry by Plasma-Enhanced Atomic Layer Deposition and Its Application in SiOx/SiO2 Super-Lattice, Nanomaterials. 9 (2019) 55. https://doi.org/10.3390/nano9010055.

[19] L.W. Hobbs, C.E. Jesurum, V. Pulim, B. Berger, Local topology of silica networks, Philosophical Magazine A. 78 (1998) 679-711. https://doi.org/10.1080/01418619808241930.

[20] J.P. Rino, I. Ebbsjö, R.K. Kalia, A. Nakano, P. Vashishta, Structure of rings in vitreous SiO 2, Physical Review B. 47 (1993) 3053-3062. https://doi.org/10.1103/PhysRevB.47.3053.

[21] J. Burgin, C. Guillon, P. Langot, F. Vallée, B. Hehlen, M. Foret, Vibrational modes and local order in permanently densified silica glasses: Femtosecond and Raman spectroscopy study, Physical Review B. 78 (2008). https://doi.org/10.1103/PhysRevB.78.184203.

[22] F.L. Galeener, Planar rings in vitreous silica, Journal of Non-Crystalline Solids. 49 (1982) 53-62.

[23] T. Deschamps, A. Kassir-Bodon, C. Sonneville, J. Margueritat, C. Martinet, D. de Ligny, A. Mermet, B. Champagnon, Permanent densification of compressed silica glass: a Raman-density calibration curve, Journal of Physics: Condensed Matter. 25 (2013) 025402. https://doi.org/10.1088/0953-8984/25/2/025402. 
[24] B. Hehlen, Inter-tetrahedra bond angle of permanently densified silicas extracted from their Raman spectra, Journal of Physics: Condensed Matter. 22 (2010) 025401. https://doi.org/10.1088/0953-8984/22/2/025401.

[25] L.P. Dávila, M.-J. Caturla, A. Kubota, B. Sadigh, T. Díaz de la Rubia, J.F. Shackelford, S.H. Risbud, S.H. Garofalini, Transformations in the Medium-Range Order of Fused Silica under High Pressure, Phys. Rev. Lett. 91 (2003) 205501. https://doi.org/10.1103/PhysRevLett.91.205501.

[26] K. Awazu, H. Kawazoe, Strained Si-O-Si bonds in amorphous SiO2 materials: A family member of active centers in radio, photo, and chemical responses, Journal of Applied Physics. 94 (2003) 6243-6262. https://doi.org/10.1063/1.1618351.

[27] R.A.B. Devine, Macroscopic and microscopic effects of radiation in amorphous SiO2, Nuclear Instruments and Methods in Physics Research Section B: Beam Interactions with Materials and Atoms. 91 (1994) 378-390. https://doi.org/10.1016/0168-583X(94)96253-7.

[28] N. Ollier, M. Lancry, C. Martinet, V. Martinez, S. Le Floch, D. Neuville, Relaxation study of predensified silica glasses under $2.5 \mathrm{MeV}$ electron irradiation, Scientific Reports. 9 (2019). https://doi.org/10.1038/s41598-018-37751-9.

[29] Q. Mei, C.J. Benmore, S. Sen, R. Sharma, J.L. Yarger, Intermediate range order in vitreous silica from a partial structure factor analysis, Physical Review B. 78 (2008). https://doi.org/10.1103/PhysRevB.78.144204.

[30] D. de Ligny, D.R. Neuville, L. Cormier, J. Roux, G.S. Henderson, G. Panczer, S. Shoval, A.-M. Flank, P. Lagarde, Silica polymorphs, glass and melt: An in situ high temperature XAS study at the Si K-edge, Journal of Non-Crystalline Solids. 355 (2009) 1099-1102. https://doi.org/10.1016/j.jnoncrysol.2008.11.038.

[31] G.S. Henderson, D.R. Neuville, B. Cochain, L. Cormier, The structure of GeO2-SiO2 glasses and melts: A Raman spectroscopy study, Journal of Non-Crystalline Solids. 355 (2009) 468-474. https://doi.org/10.1016/j.jnoncrysol.2009.01.024.

[32] K. Nagata, A. Ogura, I. Hirosawa, T. Suwa, A. Teramoto, T. Ohmi, Detection of short range order in $\mathrm{SiO}_{2}$ thin-films by grazing-incidence wide and small-angle X-ray scattering, Journal of Applied Physics. 119 (2016) 154103. https://doi.org/10.1063/1.4947053.

[33] P.Y. Huang, S. Kurasch, A. Srivastava, V. Skakalova, J. Kotakoski, A.V. Krasheninnikov, R. Hovden, Q. Mao, J.C. Meyer, J. Smet, D.A. Muller, U. Kaiser, Direct Imaging of a Two-Dimensional Silica Glass on Graphene, Nano Letters. 12 (2012) 1081-1086. https://doi.org/10.1021/nl204423x.

[34] D.R. Neuville, D. de Ligny, G.S. Henderson, Advances in Raman Spectroscopy Applied to Earth and Material Sciences, Reviews in Mineralogy and Geochemistry. 78 (2014) 509-541. https://doi.org/10.2138/rmg.2013.78.13. 
[35] R.M. Almeida, L.F. Santos, Raman Spectroscopy of Glasses, in: M. Affatigato (Ed.), Modern Glass Characterization, John Wiley \& Sons, Inc., Hoboken, NJ, USA, 2015: pp. 1-33. https://doi.org/10.1002/9781119051862.ch3.

[36] D. Lambert, C. Muehlethaler, L. Gueissaz, G. Massonnet, Raman analysis of multilayer automotive paints in forensic science: measurement variability and depth profile: Raman analysis of multilayer automotive paints in forensic science, Journal of Raman Spectroscopy. 45 (2014) 1285-1292. https://doi.org/10.1002/jrs.4490.

[37] F. Courtecuisse, C. Dietlin, C. Croutxé-Barghorn, L.G.J. Van Der Ven, Depth Characterization of Photopolymerized Films by Confocal Raman Microscopy Using an Immersion Objective, Applied Spectroscopy. 65 (2011) 1126-1132. https://doi.org/10.1366/11-06299.

[38] N. Saoula, S. Djerourou, K. Yahiaoui, K. Henda, R. Kesri, R.M. Erasmus, J.D. Comins, Study of the deposition of Ti/TiN multilayers by magnetron sputtering, Surface and Interface Analysis. 42 (2010) 1176-1179. https://doi.org/10.1002/sia.3299.

[39] S. Lee, Raman spectroscopic studies of amorphous vanadium oxide thin films, Solid State lonics. 165 (2003) 111-116. https://doi.org/10.1016/j.ssi.2003.08.022.

[40] S.V. Gaisler, O.I. Semenova, R.G. Sharafutdinov, B.A. Kolesov, Analysis of Raman spectra of amorphous-nanocrystalline silicon films, Physics of the Solid State. 46 (2004) 1528-1532. https://doi.org/10.1134/1.1788789.

[41] D. Radziuk, H. Möhwald, Ultrasonically treated liquid interfaces for progress in cleaning and separation processes, Physical Chemistry Chemical Physics. 18 (2016) 21-46. https://doi.org/10.1039/C5CP05142H.

[42] A.C. Ferrari, J. Robertson, Interpretation of Raman spectra of disordered and amorphous carbon, Physical Review B. 61 (2000) 14095-14107. https://doi.org/10.1103/PhysRevB.61.14095.

[43] H. Yamazaki, M. Koike, M. Saitoh, M. Tomita, R. Yokogawa, N. Sawamoto, M. Tomita, D. Kosemura, A. Ogura, Probing spatial heterogeneity in silicon thin films by Raman spectroscopy, Scientific Reports. 7 (2017). https://doi.org/10.1038/s41598-017-16724-4.

[44] S.S. Sarsembinov, O.Y. Prikhodko, A.P. Ryaguzov, S.Y. Maksimova, V.Z. Ushanov, Differences in local structure between amorphous As Se films prepared by different methods, Semiconductor Science and Technology. 17 (2002) 1072-1074. https://doi.org/10.1088/0268-1242/17/10/307.

[45] P. Němec, V. Nazabal, A. Moreac, J. Gutwirth, L. Beneš, M. Frumar, Amorphous and crystallized Ge-Sb-Te thin films deposited by pulsed laser: Local structure using Raman scattering spectroscopy, Materials Chemistry and Physics. 136 (2012) 935-941. https://doi.org/10.1016/j.matchemphys.2012.08.024. 
[46] L. Gasparov, T. Jegorel, L. Loetgering, S. Middey, J. Chakhalian, Thin film substrates from the Raman spectroscopy point of view: Thin film substrates-Raman spectroscopy point of view, Journal of Raman Spectroscopy. 45 (2014) 465-469. https://doi.org/10.1002/jrs.4487.

[47] A. Ramoji, K. Galler, U. Glaser, T. Henkel, G. Mayer, J. Dellith, M. Bauer, J. Popp, U. Neugebauer, Characterization of different substrates for Raman spectroscopic imaging of eukaryotic cells: Characterization of different substrates for Raman spectroscopic imaging of eukaryotic cells, Journal of Raman Spectroscopy. 47 (2016) 773-786. https://doi.org/10.1002/jrs.4899.

[48] S. Degioanni, A.M. Jurdyc, A. Cheap, B. Champagnon, F. Bessueille, J. Coulm, L. Bois, D. Vouagner, Surface-enhanced Raman scattering of amorphous silica gel adsorbed on gold substrates for optical fiber sensors, Journal of Applied Physics. 118 (2015) 153103. https://doi.org/10.1063/1.4933280.

[49] S. Novikov, L. Khriachtchev, Surface-Enhanced Raman Scattering of Silicon Nanocrystals in a Silica Film, Scientific Reports. 6 (2016). https://doi.org/10.1038/srep27027.

[50] D. Caffrey, A. Zhussupbekova, R.K. Vijayaraghavan, A. Ainabayev, A. Kaisha, G. Sugurbekova, I.V. Shvets, K. Fleischer, Crystallographic Characterisation of Ultra-Thin, or Amorphous Transparent Conducting Oxides-The Case for Raman Spectroscopy, Materials. 13 (2020) 267. https://doi.org/10.3390/ma13020267.

[51] F.L. Galeener, J.C. Mikkelsen, R.H. Geils, W.J. Mosby, The relative Raman cross sections of vitreous $\mathrm{SiO}_{2}, \mathrm{GeO}_{2}, \mathrm{~B}_{2} \mathrm{O}_{3}$, and $\mathrm{P}_{2} \mathrm{O}_{5}$, Applied Physics Letters. 32 (1978) 34-36. https://doi.org/10.1063/1.89823.

[52] P. Borowicz, M. Latek, J. Ratajczak, Deep-ultraviolet Raman investigation of silicon oxide: thin film on silicon substrate versus bulk material, Adv. Nat. Sci: Nanosci. Nanotechnol. (2012). https://doi.org/10.1088/2043-6262/3/4/045003.

[53] P. Paatero, U. Tapper, Positive matrix factorization: A non-negative factor model with optimal utilization of error estimates of data values, Environmetrics. 5 (1994) 111-126. https://doi.org/10.1002/env.3170050203.

[54] D.D. Lee, H.S. Seung, Learning the parts of objects by non-negative matrix factorization, Nature. 401 (1999) 788-791. https://doi.org/10.1038/44565.

[55] G. Laurent, W. Woelffel, V. Barret-Vivin, E. Gouillart, C. Bonhomme, Denoising applied to spectroscopies - part I: concept and limits, Applied Spectroscopy Reviews. 54 (2019) 602-630. https://doi.org/10.1080/05704928.2018.1523183.

[56] W.J. Malfait, V.P. Zakaznova-Herzog, W.E. Halter, Quantitative Raman spectroscopy: Hightemperature speciation of potassium silicate melts, Journal of Non-Crystalline Solids. 353 (2007) 4029-4042. https://doi.org/10.1016/j.jnoncrysol.2007.06.031. 
[57] W. Woelffel, C. Claireaux, M.J. Toplis, E. Burov, É. Barthel, A. Shukla, J. Biscaras, M.-H. Chopinet, E. Gouillart, Analysis of soda-lime glasses using non-negative matrix factor deconvolution of Raman spectra, Journal of Non-Crystalline Solids. 428 (2015) 121-131. https://doi.org/10.1016/j.jnoncrysol.2015.08.016.

[58] J. Du, J.M. Rimsza, Atomistic computer simulations of water interactions and dissolution of inorganic glasses, Npj Materials Degradation. 1 (2017). https://doi.org/10.1038/s41529-0170017-y.

[59] A.K. Varshneya, J.C. Mauro, Fundamentals of Inorganic Glasses, Elsevier. (2019). https://doi.org/10.1016/B978-0-12-816225-5.00017-1.

[60] G. Holzlechner, M. Kubicek, H. Hutter, J. Fleig, A novel ToF-SIMS operation mode for improved accuracy and lateral resolution of oxygen isotope measurements on oxides, Journal of Analytical Atomic Spectrometry. 28 (2013) 1080. https://doi.org/10.1039/c3ja50059d.

[61] Z. Wang, B. Liu, E.W. Zhao, K. Jin, Y. Du, J.J. Neeway, J.V. Ryan, D. Hu, K.H.L. Zhang, M. Hong, S. Le Guernic, S. Thevuthasan, F. Wang, Z. Zhu, Argon Cluster Sputtering Source for ToF-SIMS Depth Profiling of Insulating Materials: High Sputter Rate and Accurate Interfacial Information, Journal of The American Society for Mass Spectrometry. 26 (2015) 1283-1290. https://doi.org/10.1007/s13361-015-1159-1.

[62] L. Colombin, H. Charlier, A. Jelli, G. Debras, J. Verbist, Penetration of tin in the bottom surface of float glass: A synthesis, Journal of Non-Crystalline Solids. 38-39 (1980) 551-556. https://doi.org/10.1016/0022-3093(80)90494-9.

[63] G.E. Walrafen, P.N. Krishnan, Model analysis of the Raman spectrum from fused silica optical fibers, Applied Optics. 21 (1982) 359. https://doi.org/10.1364/AO.21.000359.

[64] A. Pasquarello, R. Car, Identification of Raman Defect Lines as Signatures of Ring Structures in Vitreous Silica, Physical Review Letters. 80 (1998) 5145-5147. https://doi.org/10.1103/PhysRevLett.80.5145.

[65] A. Winterstein-Beckmann, D. Möncke, D. Palles, E.I. Kamitsos, L. Wondraczek, A Ramanspectroscopic study of indentation-induced structural changes in technical alkali-borosilicate glasses with varying silicate network connectivity, Journal of Non-Crystalline Solids. 405 (2014) 196-206. https://doi.org/10.1016/j.jnoncrysol.2014.09.020.

[66] N.J. Everall, Confocal Raman Microscopy: Performance, Pitfalls, and Best Practice: Invited Lecture at the Symposium "50 Years of SAS: Looking to the Future with Vibrational Spectroscopy" at Pittcon 2008, New Orleans, Louisiana, Applied Spectroscopy. 63 (2009) 245A262A. https://doi.org/10.1366/000370209789379196. 
[67] C. Martinet, A. Kassir-Bodon, T. Deschamps, A. Cornet, S. Le Floch, V. Martinez, B. Champagnon, Permanently densified $\mathrm{SiO}_{2}$ glasses: a structural approach, Journal of Physics: Condensed Matter. 27 (2015) 325401. https://doi.org/10.1088/0953-8984/27/32/325401.

[68] C. Martinet, M. Heili, V. Martinez, G. Kermouche, G. Molnar, N. Shcheblanov, E. Barthel, A. Tanguy, Highlighting the impact of shear strain on the $\mathrm{SiO} 2$ glass structure: From experiments to atomistic simulations, Journal of Non-Crystalline Solids. 533 (2020) 119898. https://doi.org/10.1016/j.jnoncrysol.2020.119898.

[69] N.S. Shcheblanov, B. Mantisi, P. Umari, A. Tanguy, Detailed analysis of plastic shear in the Raman spectra of SiO2 glass, Journal of Non-Crystalline Solids. 428 (2015) 6-19. https://doi.org/10.1016/j.jnoncrysol.2015.07.035.

[70] P. Liu, X. Zhou, Y. Li, M. Li, D. Yu, J. Liu, The application of principal component analysis and non-negative matrix factorization to analyze time-resolved optical waveguide absorption spectroscopy data, Anal. Methods. 5 (2013) 4454. https://doi.org/10.1039/c3ay40146d.

[71] G. Casalino, N. Del Buono, C. Mencar, Nonnegative Matrix Factorizations for Intelligent Data Analysis, in: G.R. Naik (Ed.), Non-Negative Matrix Factorization Techniques, Springer Berlin Heidelberg, Berlin, Heidelberg, 2016: pp. 49-74. https://doi.org/10.1007/978-3-662-48331-2_2.

[72] J. Fonné, E. Burov, E. Gouillart, S. Grachev, H. Montigaud, D. Vandembroucq, Interdiffusion between silica thin films and soda-lime glass substrate during annealing at high temperature, Journal of the American Ceramic Society. 102 (2019) 3341-3353. https://doi.org/10.1111/jace.16154.

[73] W.S. Yoo, K. Kang, T. Ueda, T. Ishigaki, H. Nishigaki, N. Hasuike, H. Harima, M. Yoshimoto, C.S. Tan, Characterization of Hetero-Epitaxial Ge Films on Si Using Multiwavelength Micro-Raman Spectroscopy, ECS Journal of Solid State Science and Technology. 4 (2015) P9-P15. https://doi.org/10.1149/2.0041502jss.

[74] F.L. Galeener, Band limits and the vibrational spectra of tetrahedral glasses, Physical Review B. 19 (1979) 4292-4297. https://doi.org/10.1103/PhysRevB.19.4292.

[75] P. McMillan, B. Piriou, R. Couty, A Raman study of pressure-densified vitreous silica, The Journal of Chemical Physics. 81 (1984) 4234-4236. https://doi.org/10.1063/1.447455.

[76] N.S. Shcheblanov, M.E. Povarnitsyn, K.N. Mishchik, A. Tanguy, Raman spectroscopy of femtosecond multipulse irradiation of vitreous silica: Experiment and simulation, Physical Review B. 97 (2018). https://doi.org/10.1103/PhysRevB.97.054106.

[77] A. Perriot, D. Vandembroucq, E. Barthel, V. Martinez, L. Grosvalet, Ch. Martinet, B. Champagnon, Raman Microspectroscopic Characterization of Amorphous Silica Plastic Behavior, Journal of the American Ceramic Society. 89 (2006) 596-601. https://doi.org/10.1111/j.1551-2916.2005.00747.x. 
[78] R. Saavedra, M. León, P. Martin, D. Jiménez-Rey, R. Vila, S. Girard, A. Boukenter, Y. Ouerdane, Raman measurements in silica glasses irradiated with energetic ions, AIP Conference Proceedings. 1624 (2014) 118-124. https://doi.org/10.1063/1.4900466.

[79] C. Martinet, V. Martinez, C. Coussa, B. Champagnon, M. Tomozawa, Radial distribution of the fictive temperature in pure silica optical fibers by micro-Raman spectroscopy, Journal of Applied Physics. 103 (2008) 083506. https://doi.org/10.1063/1.2905321.

[80] P.N. Sen, M.F. Thorpe, Phonons in A X 2 glasses: From molecular to band-like modes, Physical Review B. 15 (1977) 4030-4038. https://doi.org/10.1103/PhysRevB.15.4030.

[81] C. Weigel, M. Foret, B. Hehlen, M. Kint, S. Clément, A. Polian, R. Vacher, B. Rufflé, Polarized Raman spectroscopy of v - SiO 2 under rare-gas compression, Physical Review B. 93 (2016). https://doi.org/10.1103/PhysRevB.93.224303.

[82] L. Martinu, D. Poitras, Plasma deposition of optical films and coatings: A review, Journal of Vacuum Science \& Technology A: Vacuum, Surfaces, and Films. 18 (2000) 2619-2645. https://doi.org/10.1116/1.1314395.

[83] A. Durandet, D.R. McKenzie, Effect of ion energy on the optical and structural properties of SiO 2 grown by plasma-enhanced chemical-vapor deposition, Journal of Applied Physics. 80 (1996) 4707-4714. https://doi.org/10.1063/1.363428.

[84] D. Goghero, A. Goullet, G. Borvon, G. Turban, Effect of the ion bombardment energy on silicon dioxide films deposited from oxygen/tetraethoxysilane plasmas in a helicon reactor, Thin Solid Films. 471 (2005) 123-127. https://doi.org/10.1016/j.tsf.2004.04.065.

[85] R.A.B. Devine, M. Marchand, Evidence for structural similarities between chemical vapor deposited and neutron irradiated $\mathrm{SiO}_{2}$, Applied Physics Letters. 63 (1993) 619-621. https://doi.org/10.1063/1.109968.

[86] S. Ponton, F. Dhainaut, H. Vergnes, D. Samelor, D. Sadowski, V. Rouessac, H. Lecoq, T. Sauvage, B. Caussat, C. Vahlas, Investigation of the densification mechanisms and corrosion resistance of amorphous silica films, Journal of Non-Crystalline Solids. 515 (2019) 34-41. https://doi.org/10.1016/j.jnoncrysol.2019.04.005.

[87] B.S. Bhumbra, Improvements in the wavelength stability of evaporated $\mathrm{TiO} 2 / \mathrm{SiO} 2$ antireflection coatings by ion assistance*, Journal of Vacuum Science \& Technology B: Microelectronics and Nanometer Structures. 13 (1995) 881. https://doi.org/10.1116/1.588200.

[88] W.A. Pliskin, Comparison of properties of dielectric films deposited by various methods, Journal of Vacuum Science and Technology. 14 (1977) 1064-1081. https://doi.org/10.1116/1.569413. 